\title{
Smart polymer nanocomposites: A review
}

\author{
W. S. Chow ${ }^{1,2}$, Z. A. Mohd Ishak ${ }^{1,2^{*}}$ \\ ${ }^{1}$ School of Materials and Mineral Resources Engineering, Engineering Campus, Universiti Sains Malaysia, Nibong Tebal \\ 14300 Penang, Malaysia \\ ${ }^{2}$ Cluster for Polymer Composites, Science and Engineering Research Centre, Engineering Campus, Universiti Sains \\ Malaysia, Nibong Tebal 14300 Penang, Malaysia
}

Received 15 September 2019; accepted in revised form 4 December 2019

\begin{abstract}
The development of smart polymer nanocomposites (SPN) has been an area of high scientific and industrial interest in recent years, due to fantastic improvements achieved in these materials. SPN found potential applications in shape memory, self-healing, self-sensing, self-heating, self-cleaning, and energy harvesting. This mini-review highlights the current research and development on SPN, specifically on shape memory polymer (SMP) and self-healing polymer (SHP) nanocomposites. The processing techniques for SPN nanocomposites, for example, polymerization, melt-compounding, solution mixing, electrospinning, and thermoset-curing are discussed. Some of the potential strategies to modify the properties of SMP and SHP nanocomposites are highlighted. The future perspective and recommended works for the SPN nanocomposites are shared in this mini-review.
\end{abstract}

Keywords: smart polymers, nanocomposites, shape memory polymers, self-healing polymers

\section{Introduction}

The smartness of material development always comes from the inspiration and intelligence of nature. Smart materials can be defined as materials that incorporate the functions of sensing, actuation, and control [1, 2]. Smart materials are attracting increasing interest especially in the era of the fourth industrial revolution (Industry 4.0) and circular economy. Smart polymer nanocomposites (SPN) which can be derived from shape memory polymer [3-6], stimuli-active polymers [7], smart electrorheological (ER) and magnetorheological (MR) polymer [8-11], self-healing polymer [12,13], self-cleaning polymer [14-17], self-heating polymer [18], self-sensing polymer [19], energy-harvesting and energy storage polymer [2027] are the latest hot research topics. The addition of nanofiller can increase the performance of the SPN (e.g., shape fixity, shape recovery, self-healing ability) due to their high specific surface area, nucleating effects, reinforcing effects, and inherent functionalities (e.g., thermal conductivity, electrical conductivity) [3]. SPNs are widely used in various applications, for example, sensor and actuator [28-33], stretchable electronic [34], wearable electronics, and smart textiles $[35,36]$, drug carrier and delivery [37, 38], aircraft and aerospace applications [39, 40].

Ten years ago, Ratna and Karger-Kocsis [41] has documented a review on shape memory polymers and composites. When revisiting the 'future outlook' from Ratna and Karger-Kocsis [41], they 'forecasted' that the blending and interpenetrating network-based polymers in SMP could have lead to the development of newer and novel SMPs. They also 'predicted' that SMPs are going to be the future materials for deployable structures for aircraft and spacecraft applications. And, nowadays there are numerous research publications dealing with SMP via blending and interpenetrating network strategies. 
This mini-review on smart polymer nanocomposites is mainly focused on the shape memory polymer (SMP) and self-healing polymer (SHP), which is part of the 'heritage' from Professor Karger-Kocsis. This article provides a basic fundamental and idea on how to fabricate SPN with different types of processing techniques. This could benefit for researchers (especially 'beginners') who are looking for feasible method to synthesis and prepare SPN, using as simple as solvent casting and melt blending, to some sophisticated methods (e.g., electrospinning, 3D and 4D printing).

\section{Smart polymer nanocomposites}

\subsection{Shape memory polymer}

Shape memory polymer (SMP) possesses the capability to fix temporary shape and recover its original shape upon subjected to external stimuli. The stimuli for shape memory alloy (SMA) is always limited to heat (e.g., Joule heating) and magnetic field, whereas there are more 'triggering choice' for SMP, e.g., light, water, solvent, $\mathrm{pH}$, temperature, electricity [42-46].
Furthermore, compared with SMA, most of the SMP has more advantages, for example, low density, high elastic deformation, good biocompatibility and biodegradability, as well as fantastic tailor-ability.

In general, SMP consists of permanent net-points (a stable polymer network) and molecular switches of reversible nature. The former memorizes the original shape while the latter are used for setting the temporary shape $[47,48]$. The permanent net-points of SMP can be formed by molecule entanglement, crystalline phase, chemical cross-linking, or interpenetrated network. Normally, thermo-sensitive SMP containing physical (or chemical) network-points, which determine their original shape, while each temporary shape is fixed by switching domains associated to a thermal transition temperature ( $\left.T_{\text {trans }}\right)$, which can be crystallization/melting transition, vitrification/glass transition, liquid crystal anisotropic/isotropic transition, reversible molecule cross-linking, and supramolecular association/disassociation [49]. The essential performance parameters for an SMP include $T_{\text {trans, }}$ shape fixity ratio $\left(R_{\mathrm{f}}\right)$ and shape recovery ratio

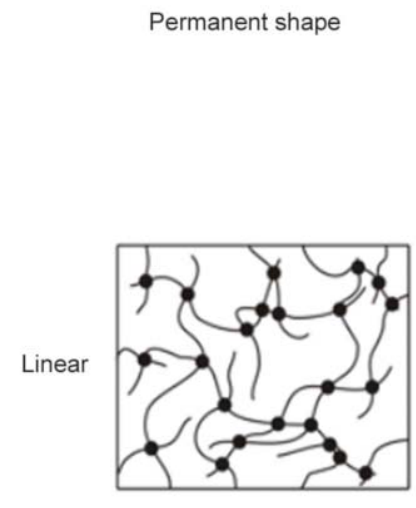

Permanent shape

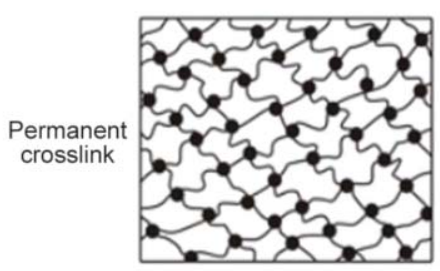

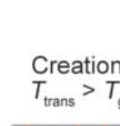
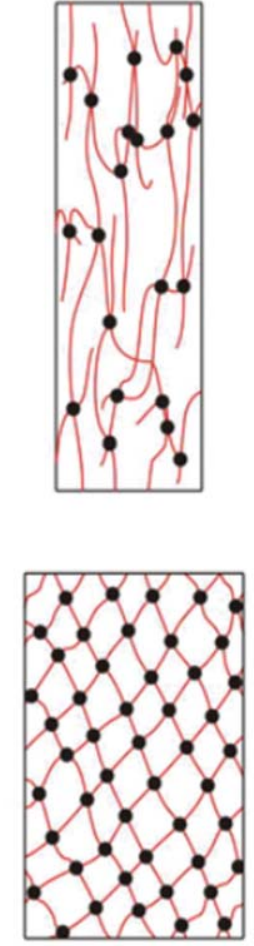

Net points
Temporary shape

Fixation

$T<T_{g}$
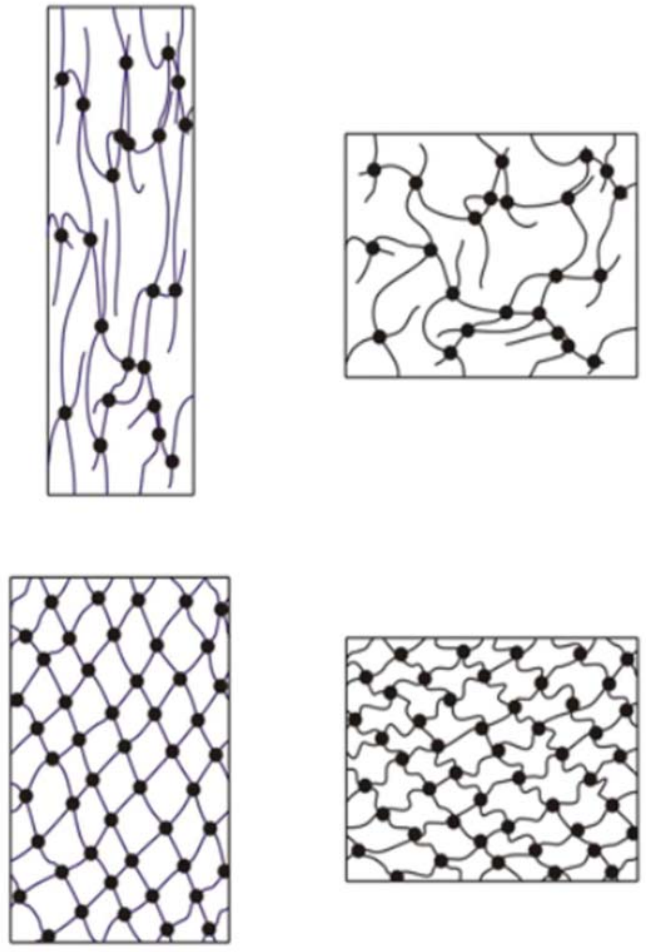

Permanent shape

Recovery

$T_{\text {trans }}>T_{g}$

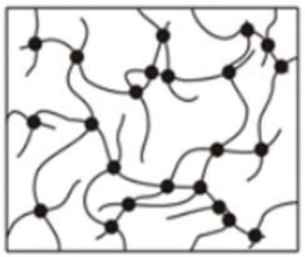

Switching segments

Figure 1. Molecular mechanisms of the thermally-induced one way shape memory (1W-SM) effect in amorphous linear (thermoplastic) and crosslinked (thermoset) polymers. Note: temporary shape is created by tensile deformation (reproduced from Karger-Kocsis and Kéki [51]). 
$\left(R_{\mathrm{r}}\right)$. The viscoelastic and relaxation behaviors of SMP are attributed to the cooperative relaxation of each component. The working mechanism in the thermoresponsive SMP is governed by both of the internal recovery stress and stored mechanical energy [50].

Figure 1 shows the molecular mechanisms of the thermally-induced one way shape memory effect in amorphous linear thermoplastic and crosslinked thermoset polymers [51]. The polymers that are used for designing shape-memories are divided into thermoplastic and thermoset. In general, thermoset SMPs can store more energy and endure more cycles (shapechanging) than thermoplastic ones due to the crosslinked bonds. Nonetheless, thermoplastic SMP can be manufactured by a facile processing method [52]. Figure 2 shows general shape memory behavior of thermally triggered SMP [53]. At heating of programmed samples, the viscoelastic forces and stored entropic will be used for recovery of temporary shape back to original shape, while the $T_{\mathrm{g}}$ or $T_{\mathrm{m}}$ is used for switching mechanism.

Conventionally, SMP can be triggered by singleand/or dual-stimuli. Nowadays, SMP can be triggered by multiple stimuli. Consequently, multi-responsive SMP is more fascinating and thus, it gives more opportunity to be used in diversified applications [54]. The introduction of nanofiller to SMP can unlock their potential for the integration of multiple stimulus methods, such as electro-activated, magnetic field actuated, light-responsive, near-infrared activated, water-induced, and thermal-responsive [55, 56]. Nanofillers can improve the mechanical performance and shape recovery stress of SMP through physical blending, in-situ polymerization and chemical cross-linking [49]. For example, the addition of carbon nanotube (CNT) and graphene nanoplatelet is capable of converting the electrical current into heat through Joule effect and thus actuating the SMP [3]. SMP nanocomposites can be used in electrochemical devices, biomimetic devices, actuators and sensors, active sound-absorbing materials, smart textiles, smart windows, deployable space structures, morphing aircraft, artificial muscle, civil and architecture applications $[57,58]$.

SMP based on biopolymer is worth to mention because this kind of successful SMP can offer good biodegradability and compostability, which is in line with sustainable development [59]. Karger-Kocsis and Kéki [51] had documented a review of biodegradable polyester-based shape memory polymers. SMP

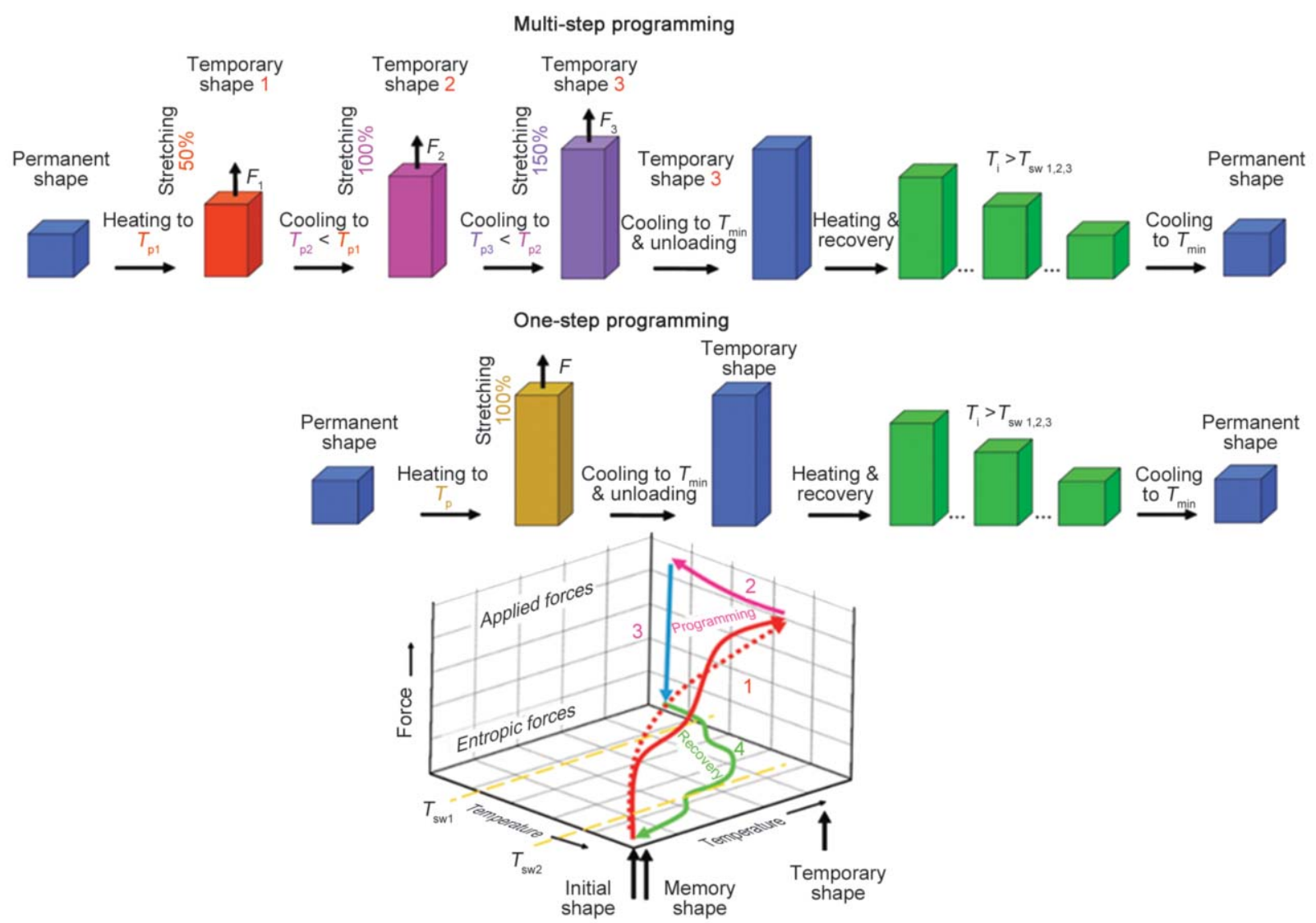

Figure 2. General shape memory behavior of thermally triggered polymer material (reproduced from Kolesov et al. [53]). 


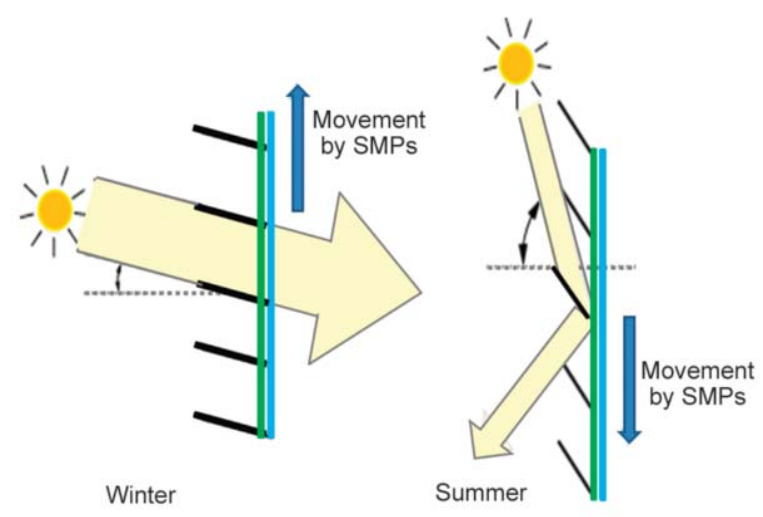

Figure 3. Schematic diagram of thermally responsive SMP in heat controls of window blinds (reproduced from Li et al. [60]).

based on biodegradable polyesters that are designed for medical devices application (e.g., sutures, stents, catheters) should be present only temporarily in human body. The future development of biodegradable polyester-SMP should focus on switching temperature for human body, improvement of shape memory effect (e.g., shape recovery), degradability and recyclability.

For readers to understand the SMP usage in daily life, here we show an example of SMP used in window blinds, which is documented in the review by Li et al. [60]. One of the feasible approaches to enhance building energy efficiency is to develop dynamic building envelope systems that can tune their thermal and optical properties based on seasonal or daily climatic changes. In this context, the external stimuli can be the sun positions, solar radiation levels, temperatures, and humidity. Figure 3 shows a schematic diagram of thermally responsive SMP in heat controls of window blinds. The angles of the blind slats can be 'self-adjusted' (actuated) according to the different external air temperatures during winter and summer time.

\subsection{Self-healing polymer}

Self-healing polymer (SHP) is one type of smart materials that can demonstrate healing-ability, in-situ damage repairing, and properties restoring. This prolongs the service life, enhance the product reliability, reduce the frequency of scheduled inspection, and lower the maintenance cost of the composite structures $[61,62]$.

There are two ways of healing strategies: (i) intrinsic self-healing and (ii) extrinsic self-healing. The former is able to heal the damage (e.g. cracks) by the polymer itself, where the inherently thermally reversible bonds of the material create a healing effect under external heating; while the latter is pre-embedded with healing agent (e.g., microcapsules, microvascular networks, hollow fibers) [63, 64].

Self-healing technology can be applied for thermoplastic and thermoset systems. Vijayan and AlMaadeed [65] had documented a review on the selfhealing epoxy composites and coating. The nature of the 'container' (which containing healing agent) such as the material, shell wall thickness, storage stability, and its response to the external stimulations (e.g., mechanical impact) are of great importance in determining the self-healing efficiency.

To demonstrate the extrinsic self-healing technology and the importance of nanofiller for SHP nanocomposites, here we give an example of SHP nanocomposites for outer space application. One of the major challenges for space missions is that most of the materials degrade over time under extreme environments. Aïssa et al. [66] had investigated self-healing materials on composite structures used in space environment. The self-healing materials were microcapsules containing 5-ethylidene-2-norbornene and dicyclopentadiene monomers with ruthenium Grubbs' catalyst. The self-healing materials were then mixed with an epoxy resin (epoxy prepolymer Epon 828 and curing agent Epicure 3046) and single-walled carbon nanotubes (SWCNT; loading: $2 \mathrm{wt} \%$ ) by using vacuum centrifuging technique. The obtained SHP nanocomposites were infused into the layers of woven carbon fibers reinforced polymer (CFRP). The CFRP specimens were then subjected to hypervelocity impact conditions, which is prevailing in the space environment using a home-made implosion-driven hypervelocity launcher. Figure 4 shows a typical example of color code diagram obtained for CFRP with and without SHP nanocomposites. The thickness distribution of the CFRP with SHP nanocomposites is much more homogenized compared to that of CFRP (with pure Epon 828), which indicates a good healing effect (i.e., less delamination propagation after the healing process). The healing efficiency of the CFRP (4 layers woven fiber) with SHP nanocomposites is about $83 \%$.

Intrinsic self-healing materials can undergo selfhealing processes multiple times through dynamic non-covalent interactions (e.g., hydrogen bonds, $\pi-\pi$ stacking) and dynamic covalent bonds (e.g., urea bonds, Diels-Alder bonds). Self-healing materials based on dynamic covalent bonding have advantages 


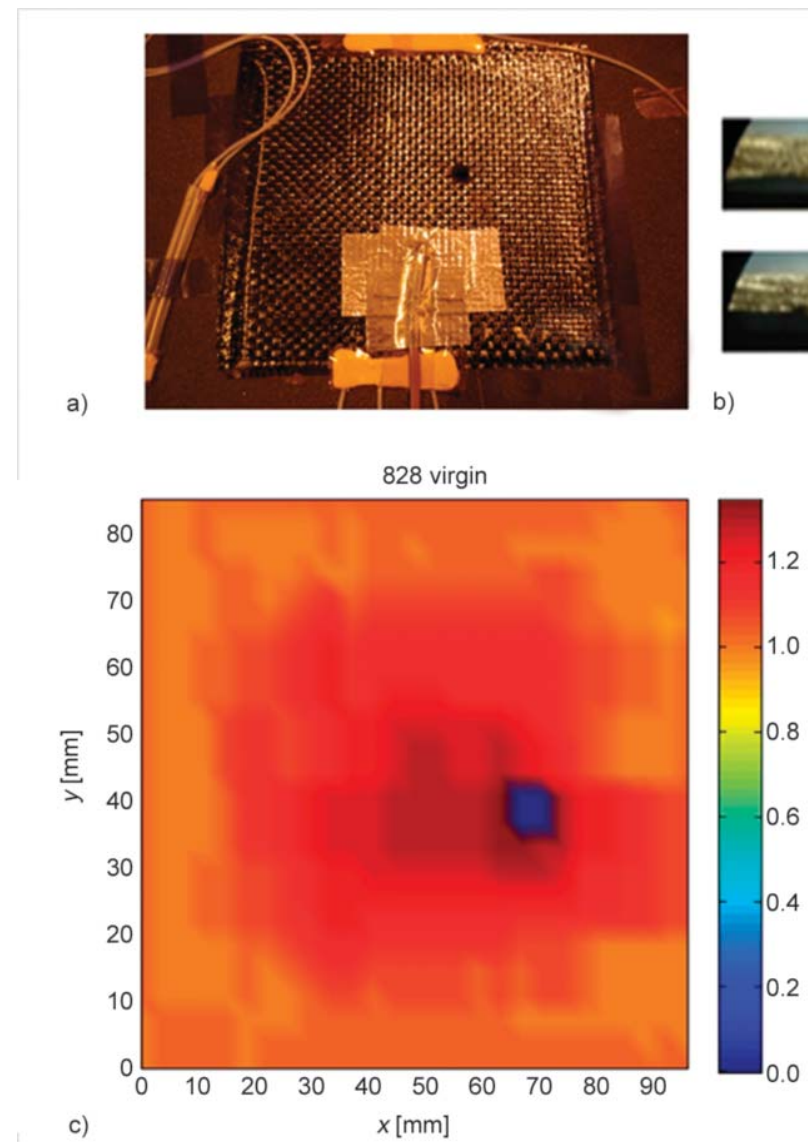

Cross-sectional views matrix
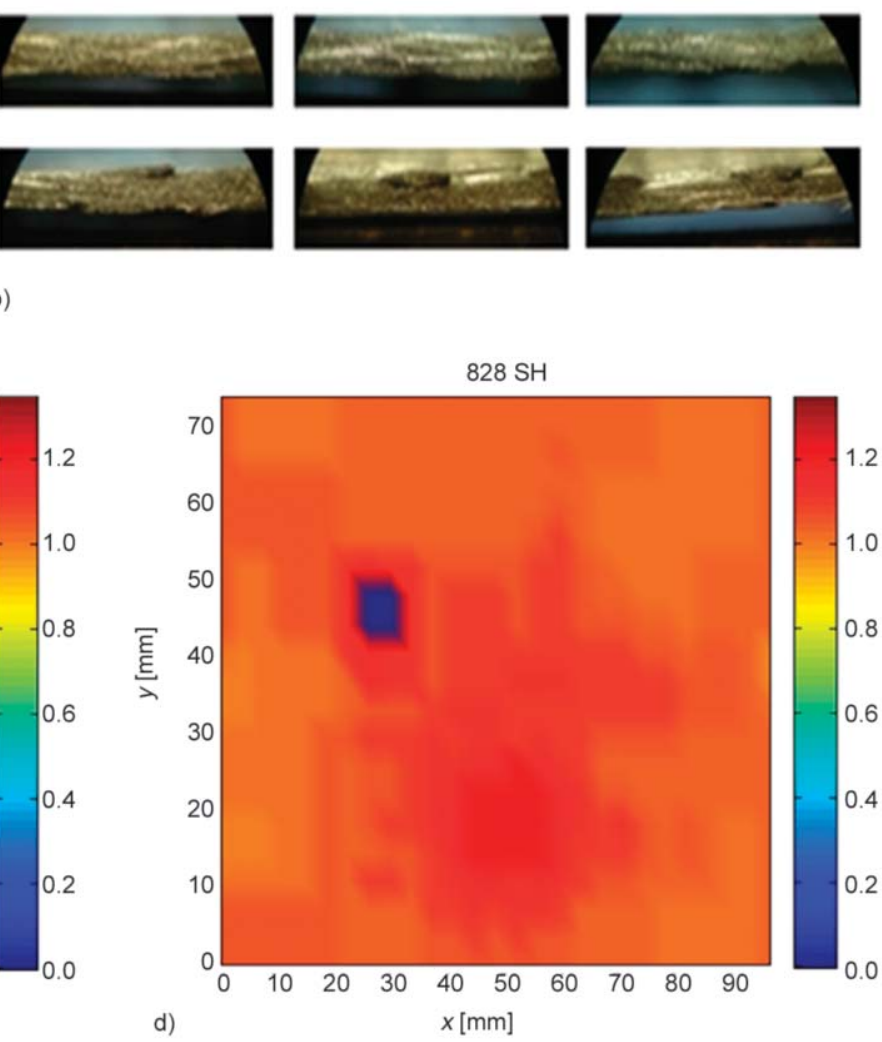

Figure 4. (a) Optical photo of the CFRP structure after impact tests, (b) representative cross-sectional view optical photos of the CFRP sample. Color code diagram simulation of the impacted sample in cases (c) with and (d) without self healing materials (reproduced from Aïssa et al. [66]).

such as high strength, increased thermal stability, and solvent resistance compared to self-healing materials based on non-covalent interactions. Zhao et al. [67] had prepared self-healing polysiloxane nanocomposite using furan-functionalized graphene as reinforcement based on Diels-Alder (DA) chemistry. The healable polysiloxane nanocomposite recovered more than $90 \%$ tensile strength and $98 \%$ elongation at break. The excellent self-healing efficiency is achieved by the reversible DA bonds between furanfunctionalized graphene and polysiloxane chains. The above mentioned intrinsic self-healing technology is potential to fabricate SHP nanocomposites with high healing performance and improved mechanical properties.

The self-healing efficiency is one of the performance indicators for the SHP nanocomposites. The effectiveness and efficiency of self-healing for SHP nanocomposites are controlled by a number of factors, e.g., the polymer matrix, the selection of nanofiller, the choices of self-healing mechanism (intrinsic or extrinsic), and the environment [68]. The concept of self-healing for other materials, e.g. cement and concrete in the construction industry (e.g., the using of extruded cementitious hollow tubes as containing/releasing devices for healing agents) and nature creatures (i.e., self-healing of starfish) can be used as an additional 'reference' for the development of SHP nanocomposites.

\section{Processing-microstructure-property}

It is quite reasonable if one mentions that most common methods used to synthesize and produce polymer nanocomposites can be used to fabricate SPNs. It is important to understand the basics of SMP and SHP nanocomposites. This mini-review gives an insight into the preparation and properties of SMP and SHP nanocomposites. Standard processing techniques including polymerization, melt blending, and solution mixing are discussed. Some of the specific preparation methods, e.g., hydrogel, electrospinning, and thermosetting are also introduced.

\subsection{Polymerization}

In the open literature, there is a number of researchers using in-situ polymerization to prepare polymer 
nanocomposites. In this mini-review, some of the current research works on synthesis of SPN are documented. You et al. [69] prepared temperature-responsive poly( $N$-isopropylacrylamide) (PNIPAm)multi-walled carbon nanotube (MWCNT) conjugates via stimuli-responsive linkages by combination reversible addition-fragmentation chain transfer (RAFT) polymerization and thiol-coupling reaction. The PNIPAm-MWCNT nanocomposites are sensitive to both temperature and bio-stimuli (e.g., glutathione concentration). Biological molecules (e.g., protein, deoxyribonucleic acid (DNA), peptide) are easily attached to carbon nanotubes (CNT) via a disulfide bond, and it can be released from CNT in the presence of external stimuli. This is important to widen the potential application of CNT vector in nano-biotechnology, nano-medicine, and drug delivery.

Narendra Kumar et al. [70] explored the thermally and magnetically initiated shape-memory properties of triple-shape nanocomposites using different shapememory creation procedures (SMCP). The SMP
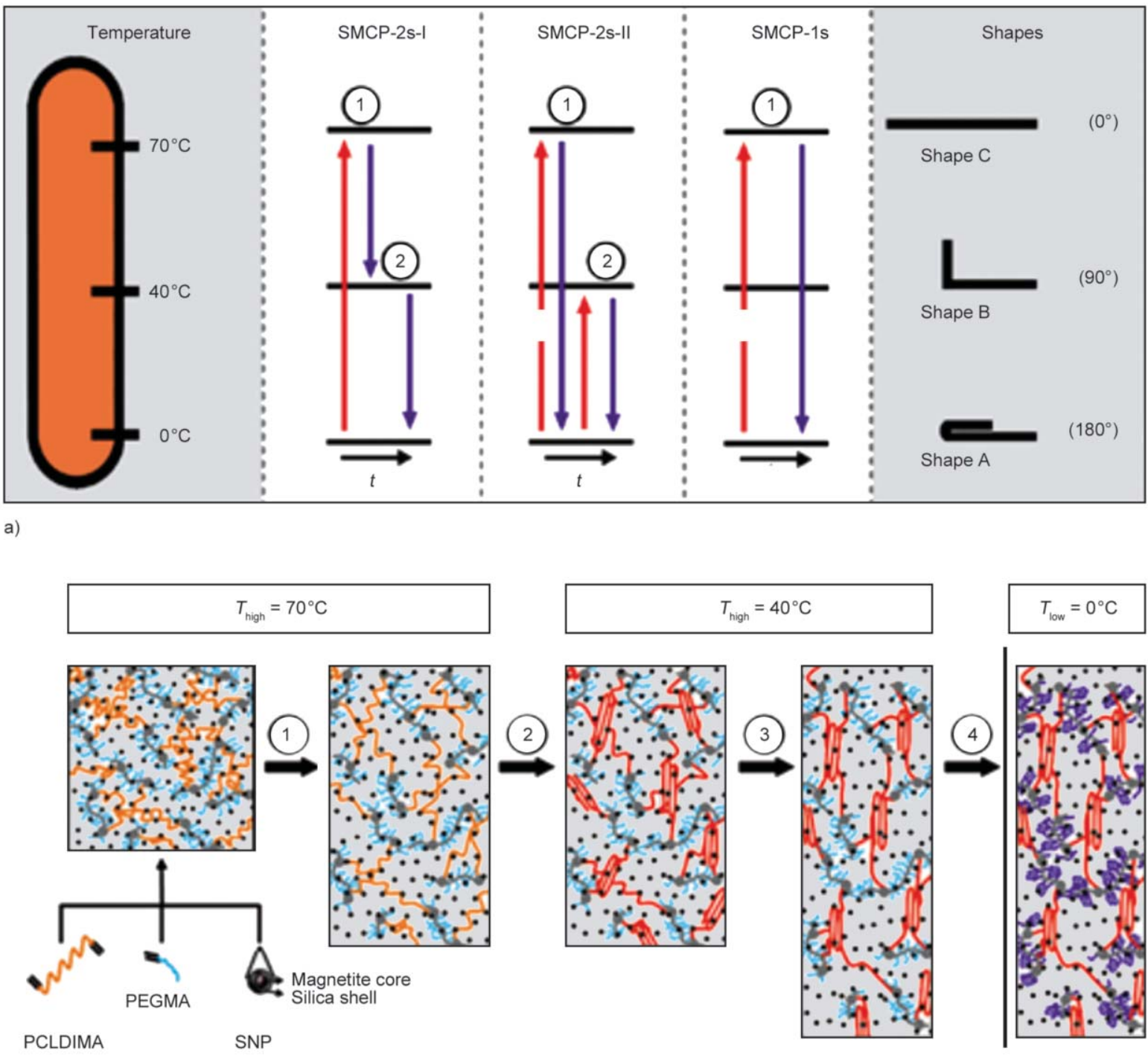

Shape C

Shape B

b)

Figure 5. (a) Schematic representations of the different shape-memory creation procedures applied for bending of the nanocomposites. Two-step programming methods: SMCP-2s-I, SMCP-2s-II as well as single-step programming procedure SMCP-1s. (b) Molecular mechanism for graft polymer network composites during shape-memory creation procedure where the color indicating the different phases of the polymer segments. Orange: amorphous PCL chain segments, Light blue: amorphous PEG chain segments, Red: crystalline PCL chain segments, Dark blue: crystalline PEG chain segments, Grey: amorphous poly(methacrylate) chain segments (reproduced from Narendra Kumar et al. [70]). 
nanocomposites consisting of crystallizable poly(ethylene glycol) (PEG) side chains, poly(e-caprolactone) (PCL), and silica-coated magnetite nanoparticles. The nanocomposites with high PEG content achieved excellent triple-shape memory effect when two-step programming procedures are used. Figure 5 shows the schematic diagrams of the various SMCP applied for bending of the nanocomposites and their molecular mechanisms [70].

Cai et al. [71] prepared PCL/polyurethane ( $\mathrm{PU}) / \mathrm{Fe}_{3} \mathrm{O}_{4}$ SMP nanocomposites by the in-situ polymerization method. The temperature at $45^{\circ} \mathrm{C}$ was selected as shape recovery temperature based on the consideration of the potential clinical application of the SMP nanocomposites. It is found that $\mathrm{PCL} / \mathrm{PU} / \mathrm{Fe}_{3} \mathrm{O}_{4} \mathrm{SMP}$ nanocomposites exhibited high shape recovery rate at $45^{\circ} \mathrm{C}$. Furthermore, in the alternating magnetic field $\left(f=45 \mathrm{kHz}, H=35.7 \mathrm{kA} \cdot \mathrm{m}^{-1}\right)$, the shape memory properties of the $\mathrm{PCL} / \mathrm{PU} / \mathrm{Fe}_{3} \mathrm{O}_{4} \mathrm{SMP}$ nanocomposites were improved by the increasing loading of $\mathrm{Fe}_{3} \mathrm{O}_{4}$, with the best recovery rate achieved $97 \%$. This suggested the potential application of PCL/PU/ $\mathrm{Fe}_{3} \mathrm{O}_{4}$ SMP nanocomposites for magnetic sensitive biomedical devices.

Kalita and Karak [72] prepared Mesua ferrea L. seed oil-based hyperbranched polyurethane (HBPU) $/ \mathrm{Fe}_{3} \mathrm{O}_{4}$ nanocomposites by in-situ polymerization technique. The HBPU nanocomposites possess full shape fixity and nearly full shape recovery under the application of microwave stimulus (microwave output power $=$ $350 \mathrm{~W}$ ). This is attributed to the frozen micro-Brownian movements of molecular chains during the vitrification. Note that the shape recovery speed increases with the increasing loading of $\mathrm{Fe}_{3} \mathrm{O}_{4}$ nanoparticles. Gao et al. [73] prepared biodegradable magnetic-sensitive shape memory PCL/ $\gamma$-(methacryloyloxy)propyl trimethoxysilane functionalized $\mathrm{Fe}_{3} \mathrm{O}_{4}$ magnetic nanoparticles (MNP) via in-situ polymerization method. In hot water bath $\left(T=60^{\circ} \mathrm{C}\right)$, the shape recovery rate and shape fixity rate of the PCL/silane functionalized $\mathrm{Fe}_{3} \mathrm{O}_{4}$ SMP nanocomposites recorded 98 and $100 \%$, respectively. In an alternating magnetic field $\left(f=60,90 \mathrm{kHz}, H=38.7,59.8 \mathrm{kA} \cdot \mathrm{m}^{-1}\right)$, the SMP nanocomposites achieved shape recovery rate in the range of 85 to $95.3 \%$. This is due to the fact that the silane functionalized $\mathrm{Fe}_{3} \mathrm{O}_{4} \mathrm{MNP}$ can act as netpoints in the network, and consequently spread out the heat uniformly in the SMP nanocomposites.

Kurd et al. [74] synthesized poly( $N$-isopropyl acrylamide-methacrylic acid-hydroxy ethyl methacrylate)
(P(NIPAm-MAA-HEM)) by emulsion polymerization. $\mathrm{Fe}_{3} \mathrm{O}_{4} \mathrm{MNP}$ and cisplatin (an anticancer chemotherapy drug) were loaded onto the nanogel by a swelling method. The P(NIPAm-MAA-HEM) nanocomposites show high drug release at low $\mathrm{pH}$ and high temperature, which are the conditions relevant to the cancer medium during hyperthermia.

Ahmadkhani et al. [75] synthesized dual responsive SNP from PEG, poly(methacrylic acid) (PMA), PNIPAm, and $\mathrm{Fe}_{3} \mathrm{O}_{4}$ nanoparticles using RAFT polymerization. The poly[(PMA-PNIPAm)m- $b$-PEG- $b$ (PNIPAm-PMA)m] triblock terpolymer micelles were capable of encapsulating doxorubicin (DOX, a common chemotherapeutic drugs). The release rate experiments of the DOX-loaded magnetic nanocomposite in two different phosphate-buffered saline (PBS) solution $(\mathrm{pH}=5.8$ and 7.4) were performed at 37 and $42^{\circ} \mathrm{C}$. Under acidic conditions $(\mathrm{pH}<\mathrm{pKa})$, the occurrence of carboxylate anions protonation in the PMA chain leads to the breaking of electrostatic interaction between PMA and DOX, and thus promoted the drug release from the nanocomposites.

Lakatos et al. [76] synthesized segmented linear PU containing Diels-Alder (DA) adduct in toluene solution from PCL (molecular weight, $M_{\mathrm{n}}=10,25$ and $50 \mathrm{~kg} / \mathrm{mol}$ ), methylene diphenyl diisocyanate (MDI), 2,4-toluene diisocyanate (TDI), 1,6-hexamethylene diisocyanate (HDI), furfurylamine (FA) and bismaleimide (BMI). The PCL(10)-MDI-FA-BMI (monomer ratio $=1: 3: 2: 2$ ) and PCL(25)-MDI-FABMI (monomer ratio $=1: 3: 2: 2$ ) exhibited shape fixity of 99 and $100 \%$, respectively after deformation at $80{ }^{\circ} \mathrm{C}$ for $80 \%$ strain. Dynamic mechanical analysis (DMA) results demonstrated a plateau-like region above $T_{\mathrm{m}}$ of PCL, and this suggested the existing of a physical network where the net-points are provided by the DA couplers-hard segments.

Abbasi et al. [77] synthesized biocompatible PU/ graphene nanoplatelet (GNp) nanocomposites from poly( $\varepsilon$-caprolactone)diol (PCL diol)/castor oil and HDI by using in-situ polymerization. The shape fixity of the PU/GNp nanocomposites is governed by the degree of crystallinity and glassy modulus. Higher loading of GNp increased the shape fixity of the nanocomposites remarkably. Besides, the shape recovery of PU/GNp (loading $=1.5 \mathrm{wt} \%$ ) recorded at $99 \%$, which is much higher than that of pure PU (shape recovery $=91 \%$ ). This is attributed to the chemical bonding of GNp and hard segment in the PU nanocomposites. 
Liu et al. [78] prepared poly(methyl methacrylate) (PMMA)/PEG semi-interpenetrating network [PMMA-PEG semi-IPN] by using radical polymerization and crosslinking of methyl methacrylate (MMA) in the presence of 2,2'-azoisobutyronitrile (AIBN) initiator, ethylene glycol dimethacrylate (EGDMA) cross-linker and linear PEG. The PMMAPEG semi-IPN exhibits two independent shape memory effects based on the $T_{\mathrm{m}}$ of the PEG crystals and the $T_{\mathrm{g}}$ of the semi-IPN. It was found that the PMMAPEG semi-IPN demonstrated an excellent recovery ratio of $99 \%$. In another study, Liu et al. [79] prepared poly((methyl methacrylate)-co-( $N$-vinyl-2pyrrolidone))/PEG) semi-IPN [P(MMA-co-NVP)/ PEG semi-IPN] by radical copolymerization of MMA with NVP in the presence of AIBN initiator, EGDMA crosslinker and linear PEG. The crosslinked P(MMAco-NVP) networks were acted as the fixed phase, whereas the amorphous PEG-PVP complex phases function as the reversible phase. The P(MMA-coNVP)/PEG semi-IPN prepared using the concept of hydrogen bonding interaction, could give SMP nanocomposites with a recovery ratio of $99 \%$.

Ghosh and Karak [80] fabricated IPN-based SPN from PU, polystyrene (PS), polystyrene grafted MWCNT (PS- $g$-MWCNT). The pristine PU/PS IPN only can heal at high microwave power input $(450 \mathrm{~W})$. Interesting to note that the PU/PS IPN containing PS- $g$-MWCNT/MWCNT exhibited excellent self-healing ability under the exposure of microwave (within 46-22 s at $300 \mathrm{~W}$ power input) and sunlight (within 318-257 s, light intensity: 0.9-1.1·10 lux). The PS- $g$-MWCNT can serve as a nano-heater in the IPN attributed to its high thermal conduction. The Brownian motions of the soft segment increase with the increasing loading of the PS- $g$-MWCNT. The higher the MWCNT loading, the higher the healing efficiency is.

\subsection{Melt compounding}

Melt processing is environmentally friendly (often solvent-free) and viable for commercial and industrial expansion. The manufacturing of polymer nanocomposites using melt compounding is a common approach. It can be achieved by readily available mixing and molding equipment, e.g., extrusion and injection molding. Yan et al. [81] melt mixed polylactide-based copolyester (PLAE) with silane coupling treated nano-SiO $\mathrm{S}_{2}$ using an intermeshing twinscrew extruder followed by injection molding. The polytetramethylene ether (PTMEG) chains and the amorphous phase of PLA are function as the soft parts, while the crystallization phase of PLA segments and nano- $\mathrm{SiO}_{2}$ are act as fixed parts of the shape memory PLAE when the temperature is above $35^{\circ} \mathrm{C}$. PLAE and its nanocomposites with low $\mathrm{SiO}_{2}$ loading content ( 1 and $3 \mathrm{wt} \%$ ) possess good shape fixity (more than 95\%) and recovery ratio (more than $87 \%$ ) with a trigger temperature around body temperature. The shape recovery is triggered by glass transition of polylactic acid (PLA) chain segments. The PLAE nanocomposites could have potential applications in biomedical areas such as smart punctual plugs because of their low trigger temperature.

$\mathrm{Gu}$ et al. [82] prepared low $T_{\mathrm{g}}$ ester-based PU $\left(T_{\mathrm{g}}=\right.$ $-34^{\circ} \mathrm{C}$ )/carbon nanotube (both pristine CNT and oxidized CNT) using melt mixing (mixing temperature: $185^{\circ} \mathrm{C}$; rotor speed: $30 \mathrm{rpm}$; mixing time: $20 \mathrm{~min}$ ). This kind of ester-based PU is suitable to be used to develop SMP nanocomposites with low trigger temperature, which have potential applications for controlling tags or proof marks in the area of frozen food. The ester groups of polyol soft segments function as reversible phases, while the elastomeric networks of the PU which consisting of hydrogenbonded urethane linkages act as fixed phases. Note that CNT (both pristine and oxidized) also can serve as an additional fixed phase due to the interaction between the CNT and the PU matrix. The shape fixity and shape recovery of the PU nanocomposites recorded above $98 \%$ for the second tensile cycle. It is worth to mention that the PU/oxidized CNT nanocomposites showed faster recovery compared to that of PU/untreated CNT counterparts. This indicates that the incorporation of oxidized CNT could promote and accelerate the recovery process due to its higher energy stored in the temporary shape.

Navarro-Baena et al. [83] prepared poly(ester-urethane)/poly(L-lactic acid) grafted cellulose nanocrystals (CNC-g-PLLA). The strain recovery and strain fixity ratio of the bionanocomposites are about $90 \%$. The improvement in the shape memory behavior is mainly attributed to the improvement in the interactions between the CNC-g-PLLA and the poly (ester-urethane). Sessini et al. [84] prepared $\mathrm{SiO}_{2}$ nanoparticles reinforced poly(ethylene-co-methacrylic acid) copolymer (PEMAA) and ionomers nanocomposites (its counterpart neutralized with sodium salt, PEMAA-Na) nanocomposites using micro-extruder equipped with twin conical co-rotating screws 
(temperature $=150{ }^{\circ} \mathrm{C}$; screw rotation speed $=$ $130 \mathrm{rpm}$; residence time $=5 \mathrm{~min})$. The PE primary crystals and the amorphous phase are function as permanent network (memorizing the original shape) while the PE secondary crystals act as switching network (fixing the temporary shape). PEMAA-Na ionomer nanocomposites (silica loading $=1 \mathrm{wt} \%$ ) showed excellent shape memory properties reaching maximum values of about 96 and $98 \%$ for strain recovery rate and strain fixity rate, respectively.

Eshkaftaki and Ghasemin [85] prepared PMMA/ PLA/GNp nanocomposites by using an internal mixer (mixing temperature: $180^{\circ} \mathrm{C}$; rotor speed: $60 \mathrm{rpm}$; mixing time: 10 minutes). At $100^{\circ} \mathrm{C}$, the shape recovery of the PLA/PMMA was increased from 93.3 to $96.7 \%$ by the addition of $1 \mathrm{phr}$ of GNp. However, there are not many changes in the shape recovery of the nanocomposites at $65^{\circ} \mathrm{C}$. A higher degree of crystallization of PLA and higher storage modulus were obtained attributed to the nucleation and reinforcement effects of GNp, and these lead to the enhancement of the shape fixity of the PMMA/ $\mathrm{PLA} / \mathrm{GNp}$ nanocomposites.

\subsection{Solution mixing}

Solution mixing is a straightforward method to prepare polymer nanocomposites, especially for a soluble polymer. The dispersion of nanofiller in the polymer prepared using solution mixing can often be enhanced by using ultra-sonification. In some of the research works, solution mixing methods are used to fast-screening for the development of polymer nanocomposites. Nevertheless, the solvent evaporation and environmental issue should be concerned. Solution casting technology has been used for the production of engineering plastics, and optical films. The advantages of this technology include uniform thickness distribution and high optical purity. Lashgari et al. [86] prepared PLLA/GNp using solution casting technique. The infrared actuated shape memory ratio of PLLA was increased from 86 to $95 \%$ by the addition of GNp. This is because the GNp can absorb
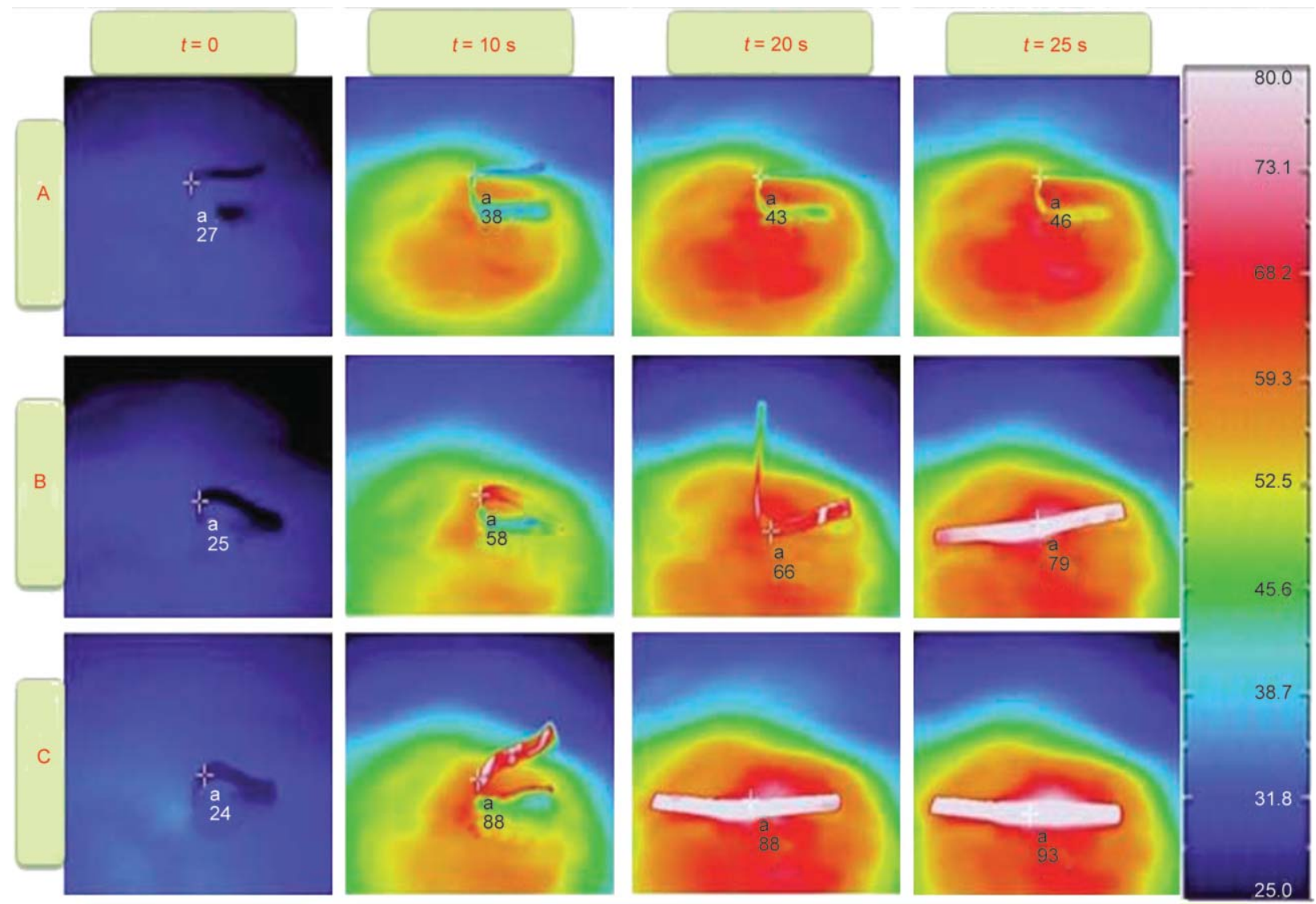

B: PLLA/GNP1,

C: PLLA/GNP6

Figure 6. Temperature distribution snapshots of pure PLLA and its nanocomposites during infrared actuation recovery (reproduced from Lashgari et al. [86]). 
infrared wave's energy and activate the shape memory of the PLLA nanocomposites. Figure 6 shows the thermo-camera images of a free recovery process in the pure PLLA, PLLA/GNp1 (PLLA filled with $1 \mathrm{wt} \% \mathrm{GNp}$ ) and PLLA/GNp6 (PLLA filled with $6 \mathrm{wt} \% \mathrm{GNp}$ ) nanocomposites actuated by infrared radiation. At 20 seconds, pure PLLA does not start recovering, but PLLA-GNp6 recovered about $90 \%$. This is due to more infrared energy is absorbed and transformed into thermal energy, in the presence of GNp.

Luo et al. [87] prepared shape memory polyurethane (SMPU) by mixing the cellulose nanowhiskers (CNW) suspension with SMPU solution in $N, N$-dimethylformamide (DMF). The PCL-diol segments function as thermally sensitive switch (due to the melting/crystallization transition), while the $\mathrm{CNW}$ percolation networks act as a water-sensitive switch (due to the reversible responsiveness to water). Consequently, the SMPU/CNW nanocomposites exhibited twin-switchable shape memory effect when applied to an aqueous-thermal-program.

Ahmed et al. [88] prepared electrically conductive MWCNT filled PU/modified PS blends using solvent casting method. The PU/modified PS/MWCNT nanocomposites demonstrated outstanding thermally- and electric field-triggered shape memory behavior to the extent of 95 and $96 \%$, respectively. The shape recovery enhancement of the PU nanocomposites was provided by CNT and the network strengthening via hydrogen bonding and urethane linkages. Zhong et al. [89] prepared gold ( $\mathrm{Au}$ ) nanoparticle filled PNIPAm-block-polypyrrole copolymer (PNIPAm- $b$-PPy) nanocomposites using amphiphilic PNIPAm-block-poly(pyrrolyl-methylstyrene) (PNIPAm- $b$-PPMS) diblock copolymers as ligands. The PNIPAm- $b$-PPy/Au nanocomposites exhibit photo-thermal effect based on strong absorption in the NIR region (due to PPy photo-thermal effects) and reversible, soluble-precipitate transition upon NIR irradiation 'on-off' (due to PNIPAm thermosensitive effects).

Qian et al. [90] fabricated vapor-grown carbon nanofibers (VGCNF) filled poly(ethylene-co-vinyl acetate) (EVA) nanocomposites through solution mixing to obtain electrical-active two-ways SMP nanocomposites. The expanding and refolding of EVA/ VGCNF (mass fraction $=15 \%$ ) nanocomposites (in strip form) can be repeated by controlling the power switch, and thus make it suitable to be used as smart actuators.

Molavi et al. [91] prepared thermally actuated tripleSMP nanocomposites based on PLA/PCL/functionalized GNp by using solution mixing method. The melting points of crystalline phases were selected as transition temperatures $\left(T_{\text {trans }}\right)$, and triple-shape memory was induced at $T_{\mathrm{m}}$, PLA, and $T_{\mathrm{m}}$, PCL. The PLA offers the hard phase for shape fixity while PCL provides the reversible phase for shape recovery. The PLA/PCL nanocomposites showed fixity ratio and recovery ratio, about 80 , and $90 \%$, respectively. A higher recovery ratio was obtained by the addition of the thermal conductive GNp (loading $=1.5 \mathrm{wt} \%$ ). Abbasi-Shirsavar et al. [92] fabricated PU/PCL/ZnO nanoparticle nanocomposites by using a solvent casting method. The shape recovery ratio of the PU/PCL nanocomposites was increased by the addition of $20 \mathrm{wt} \% \mathrm{ZnO}$. This is because some nanoparticles restrict the hard segment-soft segment interactions and thus gives more mobility to PCL, while the other $\mathrm{ZnO}$ nanoparticles act as a nucleating agent for PCL. Gu et al. [93] developed a dual-induced self-expandable stent based on biodegradable shape memory $\mathrm{PU} / \mathrm{Fe}_{3} \mathrm{O}_{4}$ nanocomposites by solution casting method. The stent could maintain its temporary shape at body temperature for a certain period while it was able to recover to its permanent shape at the temperature slightly above body temperature (around $40^{\circ} \mathrm{C}$ ) in both a water bath and an alternating magnetic field. The nanocomposites showed excellent shape memory properties (strain fixity ratio $\sim 100 \%$; strain recovery ratio $>82 \%$ ) at a temperature around body temperature and had considerable strength, appropriate elongation to matching the physical properties of soft biological tissues - which is suitable for biomedical application, such as cardiovascular stents.

Polymer nanocomposites membranes are widely used in water treatment, antifouling nano-filtration, gas separation, wound, and skin dressing. SMP-based skin dressing is attractive due to its unique thermoresponsive phase transition effect. It can be used to fabricate skin dressing that stripped 'automatically', without causing secondary damage on the patient skin. Zou et al. [94] prepared temperature-sensitive PNIPAm/konjac glucomannan (KGM)/graphene oxide (GO) nanocomposite membrane by using solution blending, with calcium ions as a cross-linker. 

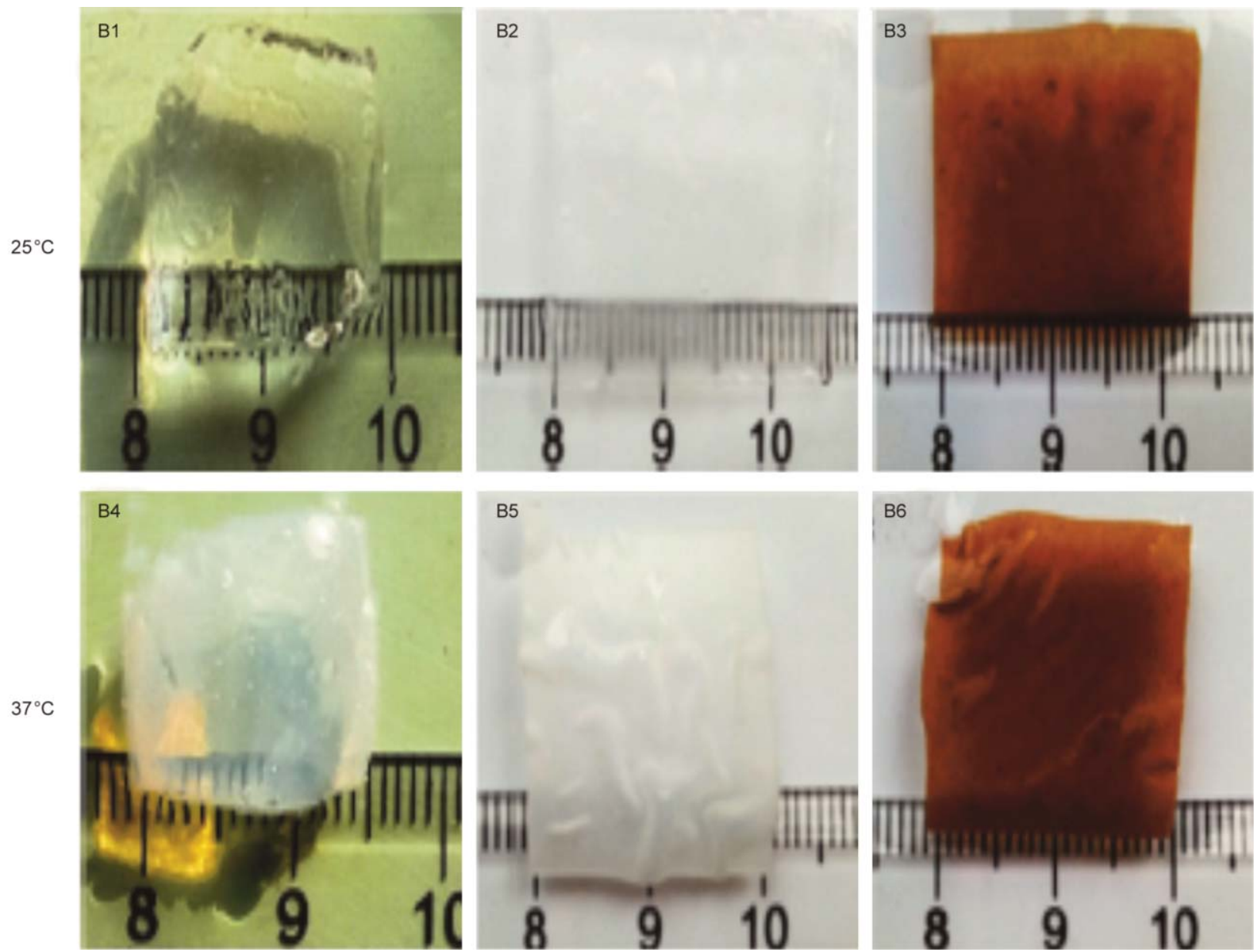

Figure 7. Digital photo of PNIPAm (B1 and B4), PNIPAm/KGM (B2 and B5), and PNIPAM/KGM/GO (B3 and B6) composite membranes with the volume conversion at 25 and $37^{\circ} \mathrm{C}$, respectively (reproduced from Zou et al. [94]).

Figure 7 shows digital photo of PNIPAm, PNIPAm/ $\mathrm{KGM}$, and PNIPAM/KGm/GO nanocomposite membranes with the volume conversion at 25 and $37^{\circ} \mathrm{C}$, respectively. At temperature below the lower critical solution temperature (LCST), the PNIPAm/KGM/ GO nanocomposite membrane was swollen, whereas, at temperature above the LCST, the membrane was shrunk. This indicates that the PNIPAm/KGM/ GO nanocomposite membrane is sensitive to temperature and it is potential to be used as smart skin dressing materials.

\subsection{Other processing techniques}

\subsubsection{Hydrogels}

Stimuli-responsive nanocomposite hydrogels possess an inherent intelligence and self-adaptation ability when subjected to different external stimuli, e.g., temperature, $\mathrm{pH}$, electric current, light, and ionic strength. Nanocomposite hydrogels have attracted much attention due to their rapid swelling-deswelling response, high swelling ratios, and tunable physical properties $[95,96]$. Stimuli-responsive hydrogels are widely used in numerous potential applications, e.g., sensor, actuators, transducers, artificial muscles, tissue engineering scaffolds, microfluidics, and drug delivery vector [97-101].

Haraguchi [102] had synthesized PNIPAm/water swellable hectorite clay by using in-situ polymerization. The addition of hectorite clay increases the stretch-ability of the PNIPAm nanocomposite hydrogel. Furthermore, the coil-to-globule transition temperature of PNIPAm nanocomposite hydrogel can be controlled by using different inorganic salt (i.e., $\mathrm{NaCl}$ ) concentration and cationic surfactant.

The incorporation of superparamagnetic iron oxide $\left(\mathrm{Fe}_{3} \mathrm{O}_{4}\right)$ nanoparticles in stimuli-responsive hydrogel can widen their biomedical application, e.g., protein immobilization, separation, and purification, magnetic resonance imaging, and biosensor. Yassine et al. [103] developed a nanocomposite gel consisting of PNIPAm and magnetic $\mathrm{Fe}_{3} \mathrm{O}_{4}$ nanobeads (NB) for controlled release of drugs upon exposure to an alternating magnetic field. The drug release study was carried out by remotely triggering the 


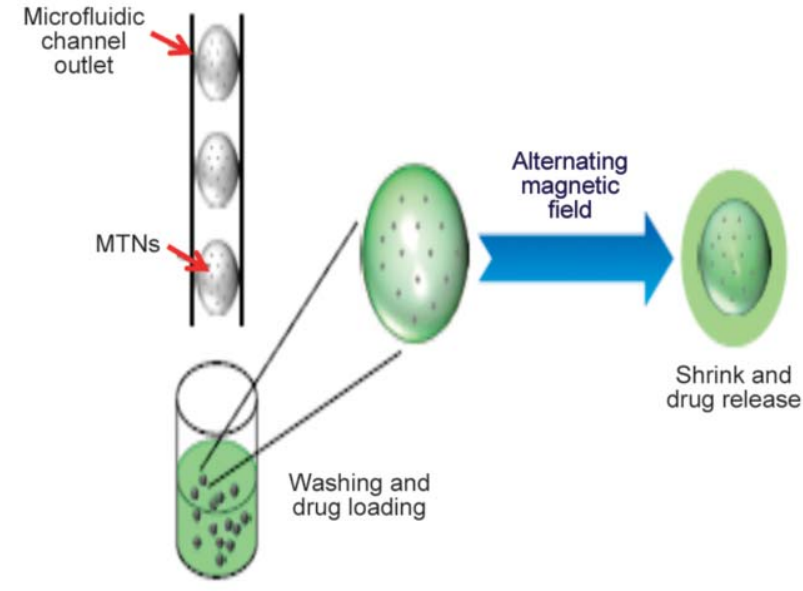

Figure 8. Principle of magnetically controlled drug release using PNIPAm microparticles with embedded iron oxide nanobeads (NB) to form monodispersed magneto-thermoresponsive nanocomposites (MTN). The MTN are fabricated in a microfluidic system and filled with a drug by means of diffusion. The heat generated by the NB upon the application of an alternating magnetic field causes the gel-structure to shrink and the release of drug (reproduced from Yassine et al. [103]).

magneto-thermoresponsive nanocomposites (MTN) with an alternating magnetic field of $72 \mathrm{mT}$ in amplitude and $600 \mathrm{kHz}$ in frequency. The principle of the magnetically controlled drug release by using PNIPAm MTN method is shown in Figure 8. It is found that the MTN can de-swell more than $80 \%$ of its initial weight within a short time (approximately 6 minutes) under an alternating magnetic field.

Ahmad et al. [104] prepared dual temperature- and pH-responsive $\mathrm{Fe}_{3} \mathrm{O}_{4} / \mathrm{SiO}_{2} /$ poly(styrene- $N$-isopropylacrylamide-methyl methacrylate-polyethylene glycol methacrylate) [P(S-NIPAm-MAA-PEGMA)] and temperature-responsive $\mathrm{Fe}_{3} \mathrm{O}_{4} / \mathrm{SiO}_{2} /$ poly(S-NIPAMmethacrylic acid-PEGMA) [P(S-NIPAm-MMAPEGMA)] nanocomposite hydrogel particles by blending $\mathrm{Fe}_{3} \mathrm{O}_{4} / \mathrm{SiO}_{2}$ nanocomposite particles with the respective hydrogel particles. Figure 9 shows the absorption behavior of trypsin (a serine protease in digestive system) by $\mathrm{Fe}_{3} \mathrm{O}_{4} / \mathrm{SiO}_{2}$ nanocomposite and $\mathrm{Fe}_{3} \mathrm{O}_{4} / \mathrm{SiO}_{2} / \mathrm{P}\left(\mathrm{S}-\mathrm{NIPAm}-\mathrm{MAA}-\mathrm{PEGMA}\right.$ ) and $\mathrm{Fe}_{3} \mathrm{O}_{4} /$ $\mathrm{SiO}_{2} / \mathrm{P}$ (S-NIPAm-MMA-PEGMA) nanocomposite hydrogel at temperature above and below the LCST. It was found that electrostatic attraction among negatively charged $\mathrm{Fe}_{3} \mathrm{O}_{4} / \mathrm{SiO}_{2}$ nanocomposite and positively charged P(S-NIPAm-MMA-PEGMA) favors the formation of magnetic nanocomposite hydrogel. Hou et al. [105] prepared near-infrared (NIR) laser switched copper sulfide (CuS)/clay/poly(oligo

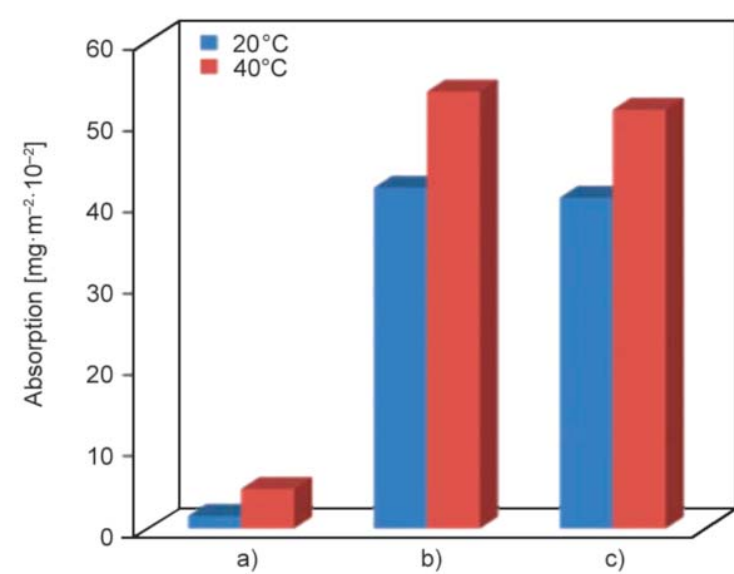

Figure 9. Bar diagram represents the amount of absorptions of trypsin on (a) $\mathrm{Fe}_{3} \mathrm{O}_{4} / \mathrm{SiO}_{2}$ nanocomposite, (b) $\mathrm{Fe}_{3} \mathrm{O}_{4} / \mathrm{SiO}_{2} / \mathrm{P}(\mathrm{S}-\mathrm{NIPAm}-\mathrm{MAA}-\mathrm{PEGMA})$ and (c) $\mathrm{Fe}_{3} \mathrm{O}_{4} / \mathrm{SiO}_{2} / \mathrm{P}$ (S-NIPAm-MMA-PEGMA) composite hydrogel particles at temperature above $\left(40^{\circ} \mathrm{C}\right)$ and below $\left(20^{\circ} \mathrm{C}\right)$ of the LCST. Absorption: immobilization $200 \mathrm{mg} / \mathrm{g}$ of particles, $\mathrm{pH}$ 10.0, immobilization time $45 \mathrm{~min}$ (reproduced from Ahmad et al. [104]).

ethylene glycol methacrylate-co-2,2-methoxyethoxy ethyl methacrylate) [poly(OEGMA-co-MEO $\left.{ }_{2} \mathrm{MA}\right)$ ] nanocomposite hydrogel by free radical polymerization. The cyclic test results proved that the poly (OEGMA-co- $\mathrm{MEO}_{2} \mathrm{MA}$ )/CuS/clay nanocomposite hydrogel exhibited stable volume transition properties. A smart liquid microvalve made by the nanocomposite hydrogel has been fabricated, and it could be remotely controlled by NIR switch effectively.

\subsubsection{Filament spinning and electrospinning}

Smart polymer ultrafine fibers have gained attention attributed to their potential application, such as electronic textiles, dust-free clothing, electromagnetic interference shielding, filtration, and biomedical use [106, 107]. Tonndorf et al. [108] prepared a laser light-sensitive yarn based on thermoplastic polyester-urethane/gold nanorods (GNR) by a wet spinning technique. The GNR was incorporated within the yarn or coating on the yarn surface by a semi-continuous layer-by-layer (LBL) technique. The lightinduced shape memory effect is triggered by a lowpowered laser $(808 \mathrm{~nm}, 2 \mathrm{~W}$ for GNR-incorporated within the yarn and $1 \mathrm{~W}$ for GNR coated thermoplastic polyester-urethane yarn). The shape memory effect of the functionalized yarns can be triggered by laser light, and it had achieved nearly $100 \%$ strain recovery. Sabzi et al. [109] utilized co-electrospinning technique to simultaneously electrospin PLA 
and poly(vinyl acetate) (PVAc), in the presence of GNp. The addition of GNp had contributed to the excellent triple-shape memory properties, where it increases the shape fixity and shape recovery of the PLA/PVAc. This is due to the dense physical croslinks and higher stored elastic deformation energy for the nanocomposites, in the presence of GNp.

\subsubsection{Thermosetting resins}

Thermosetting materials are widely used in automotive, aircraft, electronics and sports industry [110]. Thermoset-based SMPs with high heat resistance are suitable for use in high temperature environment [111]. Karger-Kocsis and Kéki [112] have documented a review of shape memory epoxies and their composites. In general, the switching or transformation temperature for thermal-activated shape memory thermosets is the $T_{\mathrm{g}}$. The shape memory performance of epoxy can be tailored by using carbon fiber fabric [47], co-continuous phase structure of the epoxy/PCL nanoweb [113] and nanofillers. Tripleshape memory effects (TSME) for thermoset SMP can be obtained by blending, IPN and hybridization. Li et al. [114] prepared triple-shape memory epoxy/ $\mathrm{SiO}_{2}$ nanocomposites with bilayer structures of wellseparated $T_{\mathrm{g}}$. The epoxy $/ \mathrm{SiO}_{2}$ exhibited outstanding TSME, in which their shape fixity was improved remarkably by the addition of $\mathrm{SiO}_{2}$ nanoparticles. Figure 10 shows the illustration of TSME of bilayer epoxy/ $\mathrm{SiO}_{2}$ nanocomposites, where 'shape $\mathrm{C}$ ' is the original shape, 'shape $\mathrm{B}$ ' is the first temporary shape and 'shape $\mathrm{A}$ ' is the second temporary shape.

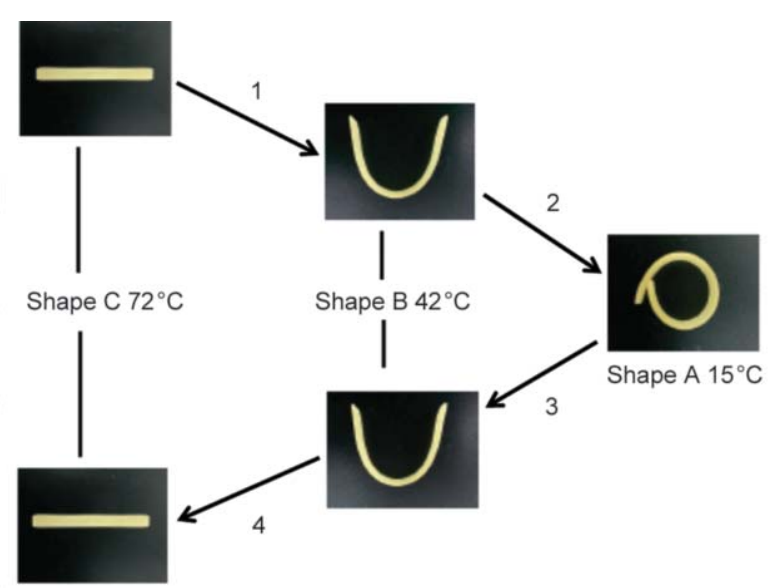

Figure 10. Illustration of triple-shape memory effect of bilayer $\mathrm{SiO}_{2}$ /epoxy nanocomposite: 'shape $\mathrm{C}$ ' is the original shape, 'shape B' is the first temporary shape and 'shape $A$ ' is the second temporary shape (reproduced from Li et al. [114]).
According to Ortiz et al. [115] the photo-curable shape memory epoxy/thiol-ene/GNp nanocomposites revealed excellent values of shape recovery and shape fixity with maximum of 98 and $99 \%$, respectively. The $T_{\mathrm{g}}$ of the co-network polyether-polythioether was function as the switching temperature. The GNp (with high thermal conductivity) and polythioethers soft domain was used to control the shape recovery and shape fixity of the epoxy nanocomposites. One of the major drawbacks of SMP is the low recovery stress, which limits the size of commercial components to a few centimeters. Consequently, the recovery stress of larger components is insufficient to counter the components' weight. Ivens et al. [116] developed large-sized components based on SMP. To achieve higher recovery stresses, asymmetric fiber reinforced shape memory composites were produced using resin transfer moulding. The rate of shape recovery is higher when the fiber reinforcement is loaded in compression. This gives us an indication that the design of fiber-reinforced SMP nanocomposites should consider the fiber orientation and deformation direction.

Reversible plasticity shape memory (RPSM) property provides an alternate 'cold' programming approach - in which it can be programmed at temperatures well below the $T_{\mathrm{g}}$ and offers several advantages over conventional 'hot' programming. The RPSM can be used for large components, and often possesses a higher recovery ratio, faster recovery rate, and improved recovery stress. Abishera et al. [117] investigated the recovery performance of coldprogrammed shape memory epoxy/CNT nanocomposites for free, partial, and completely constrained conditions. The epoxy/CNT nanocomposites achieved $100 \%$ shape recovery under free recovery conditions. Furthermore, it was found that adding CNT enhanced the shape fixity and recovery stress of the epoxy nanocomposites.

Nanofiller hybridization can be used as a feasible technique to improve the shape memory effect of polymer nanocomposites. Liang et al. [118] investigated synergistic effect of carbon nanofiber (CNF) and carbon nanofiber paper (CNFP) on the electroactuation of epoxy-based SMP nanocomposites. The shape memory effect of the SMP was improved by CNFP coating due to more CNF in the conductive networks. Lu et al. [119] studied the combination of $\mathrm{CNT}$ and boron nitride on the shape memory effect 
of epoxy nanocomposites. The synergistic effect of boron nitride and CNT was demonstrated to improve significantly the infrared light-induced shape recovery. It was found that boron nitrides could help to facilitate heat transfer in the epoxy nanocomposite due to improved thermally conductive property.

Thermoset blends strategy can be used to widen the application of SMP. The work from Tanpitaksit et al. [120] demonstrated that addition of the benzoxazine fraction could prolong the shape recovery time of the aliphatic epoxy-based SMP. The SMP achieved outstanding shape fixity value up to $99 \%$ at room temperature. At different active temperatures, i.e. $T_{\mathrm{g}}$ and $T_{\mathrm{g}}+20^{\circ} \mathrm{C}$, the SMP needed only $1-3$ minutes to fully recover to their permanent shape. The epoxy/polybenzoxazine SMP are attractive as shape-memory materials to be used in a broad range of applications such as hinge or deployable structure. This idea can be extended to SMP nanocomposites, where it is predicted that incorporation of suitable nanofiller into thermoset blends could further improve their shapememory performance.

\section{Conclusions and future perspective}

In this mini-review, special attention is given on the processing and structure properties of SMP and SHP nanocomposites. The shape memory and self-healing properties of polymer nanocomposites are controlled by the selection of polymer (thermoplastic or thermoset), selection of nanofiller (pristine or surface treatment), and processing technique (e.g., polymerization, melt-mixing or solution mixing). Some special preparation methods, e.g., hydrogel, electrospinning, thermoset curing are suitable to develop SPN. In addition, it is worth to design SPN by readily available technology, for example, using coreshell templating [121-123], foaming [124], UV curing $[125,126], 3 \mathrm{D}$ and $4 \mathrm{D}$ printing $[127,128]$. The addition of nanofiller could improve the performance of SMP and SHP nanocomposites attributed to their reinforcing-ability, nucleating-ability, and inherent functionalities (e.g., thermal conductivity, electrical conductivity). The combination of smartness of the SPN, for example, SMP with SHP functionality is possible, by creating semi-IPN consisting of crosslinked thermoset, thermoplastic, and nanofiller. The key future challenges in smart polymer nanocomposites include the optimization of polymer-nanofiller interaction, dispersibility of nanofiller in polymer matrix, and processability [129]. Multifunctional SMP and SHP nanocomposites with biocompatibility, sustainability, recyclability, ease-ofprocessing should be considered for future research work. Molecular simulations, phenomenological framework, micromechanical analysis, and finite element modeling can be applied to predict and optimize SPN performance [130, 131]. Innovative research on nanofillers should be able to benefit knowledge advancement in SNP. Smart polymer nanocomposites coupled with intelligent manufacturing technique will bring exciting breakthroughs and enormous development for the polymer engineering industry.

\section{Acknowledgements}

The authors would like to express their appreciation to Universiti Sains Malaysia for Research University Grant (1001/ PBAHAN/8014024).

\section{References}

[1] Halary J., Cookson P., Stanford J. L., Lovell P. A., Young R. J.: Smart nanostructured polymeric coatings for use as remote optical strain sensors. Advanced Engineering Materials, 6, 729-732 (2004). https://doi.org/10.1002/adem.200400061

[2] Genchi G. G., Marino A., Grillone A., Pezzini I., Ciofani G.: Remote control of cellular functions: The role of smart nanomaterials in the medicine of the future. Advanced Healthcare Materials, 6, 1700002/1-1700002/16 (2017).

https://doi.org/10.1002/adhm.201700002

[3] Pilate F., Toncheva A., Dubois P., Raquez J-M.: Shapememory polymers for multiple applications in the materials world. European Polymer Journal, 80, 268-294 (2016).

https://doi.org/10.1016/j.eurpolymj.2016.05.004

[4] Liu T., Zhou T., Yao Y., Zhang F., Liu L., Liu Y., Leng J.: Stimulus methods of multi-functional shape memory polymer nanocomposites: A review. Composites Part A: Applied Science and Manufacturing, 100, 2030 (2017).

https://doi.org/10.1016/j.compositesa.2017.04.022

[5] Homaeigohar S., Elbahri M.: Switchable plasmonic nanocomposites. Advanced Optical Materials, 7, 1801101/1-1801101/33 (2019). https://doi.org/10.1002/adom.201801101

[6] Zare M., Prabhakaran M. P., Parvin N., Ramakrishna S.: Thermally-induced two-way shape memory polymers: Mechanisms, structures, and applications. Chemical Engineering Journal, 374, 706-720 (2019). https://doi.org/10.1016/j.cej.2019.05.167 
[7] Meng H., Hu J. L.: A brief review of stimulus-active polymers responsive to thermal, light, magnetic, electric, and water/solvent stimuli. Journal of Intelligent Materials Systems and Structures, 21, 859-885 (2010). https://doi.org/10.1177/1045389X10369718

[8] Liu Y. D., Choi H. J.: Recent progress in smart polymer composite particles in electric and magnetic fields. Polymer International, 62, 147-151 (2013).

https://doi.org/10.1002/pi.4441

[9] Wang B., Liu C., Yin Y., Yu S., Chen K., Liu P., Liang B.: Double template assisting synthesized core-shell structured titania/polyaniline nanocomposite and its smart electrorheological response. Composites Science and Technology, 86, 89-100 (2013). https://doi.org/10.1016/j.compscitech.2013.07.003

[10] Sun Y., Wang Y., Yao J., Gao L., Li D-S., Liu Y.: Highly magnetic sensitivity of polymer nanocomposite hydrogels based on magnetic nanoparticles. Composites Science and Technology, 141, 40-47 (2017).

https://doi.org/10.1016/j.compscitech.2017.01.006

[11] Kim Y. H., Ahn W. J., Choi H. J., Seo Y.: Fabrication and magnetic stimuli-response of polydopamine-coated core-shell structured carbonyl iron microspheres. Colloid and Polymer Science, 294, 329-337 (2016). https://doi.org/10.1007/s00396-015-3786-2

[12] van der Zwaag S., Grande A. M., Post W., Garcia S. J., Bor T. C.: Review of current strategies to induce selfhealing behaviour in fibre reinforced polymer based composites. Materials Science and Technology, 30, 1633-1641 (2014).

https://doi.org/10.1179/1743284714Y.0000000624

[13] Thakur V. K., Kessler M. R.: Self-healing polymer nanocomposite materials: A review. Polymer, 69, 369-383 (2015). https://doi.org/10.1016/j.polymer.2015.04.086

[14] Selim M. S., El-Safty S. A., El-Sockary M. A., Hashem A. I., Abo Elenien O. M., El-Saeed A. M., Fatthallah N. A.: Smart photo-induced silicone/ $/ \mathrm{TiO}_{2}$ nanocomposites with dominant [110] exposed surfaces for selfcleaning foul-release coatings of ship hulls. Materials and Design, 101, 218-225 (2016).

https://doi.org/10.1016/j.matdes.2016.03.124

[15] Ke Y., Zhou C., Zhou Y., Wang S., Chan S., Long Y.: Emerging thermal-responsive materials and integrated techniques targeting the energy-efficient smart window application. Advanced Functional Materials, 28, 1800113/1-1800113/18 (2018).

https://doi.org/10.1002/adfm.201800113

[16] Ibrahim S., Labeeb A., Mabied A. F., Soliman O., Ward A., Abd-El-Messieh S. L., Abdelhakim A. A.: Synthesis of super-hydrophobic polymer nanocomposites as a smart self-cleaning coating films. Polymer Composites, 38, 147-156 (2017).

https://doi.org/10.1002/pc.24023
[17] Wang F., Guo Z.: Facile fabrication of ultraviolet light cured fluorinated polymer layer for smart superhydrophobic surface with excellent durability and flame retardancy. Journal of Colloid and Interface Science, 547, 153-161 (2019).

https://doi.org/10.1016/j.jcis.2019.03.095

[18] Jang S-H., Park Y-L.: Carbon nanotube-reinforced smart composites for sensing freezing temperature and deicing by self-heating. Nanomaterials and Nanotechnology, 8, 1-8 (2018).

https://doi.org/10.1177/1847980418776473

[19] Hassan H., Tallman T. N.: Failure prediction in selfsensing nanocomposites via genetic algorithm-enabled piezoresistive inversion. Structural Health Monitoring, in press (2020).

https://doi.org/10.1177/1475921719863062

[20] Dąbrowska A., Greszta A.: Analysis of the possibility of using energy harvesters to power wearable electronics in clothing. Advances in Materials Science and Engineering, 2019, 9057293/1-9057293/13 (2019). https://doi.org/10.1155/2019/9057293

[21] Yang J-H., Cho H-S., Park S-H., Song S-H., Yun K-S., Lee J. H.: Effect of garment design on piezoelectricity harvesting from joint movement. Smart Materials and Structures, 25, 035012/1-035012/15 (2016).

https://doi.org/10.1088/0964-1726/25/3/035012

[22] Zhang M., Gao T., Wang J., Liao J., Qiu Y., Xue H., Shi Z., Xiong Z., Chen L.: Single $\mathrm{BaTiO}_{3}$ nanowirespolymer fiber based nanogenerator. Nano Energy, 11, 510-517 (2015).

https://doi.org/10.1016/j.nanoen.2014.11.028

[23] Dorigato A., Canclini P., Unterberger S. H., Pegoretti A.: Phase changing nanocomposites for low temperature thermal energy storage and release. Express Polymer Letters, 11, 738-752 (2017).

https://doi.org/10.3144/expresspolymlett.2017.71

[24] Lu P., Xue D., Yang H., Liu Y.: Supercapacitor and nanoscale research towards electrochemical energy storage. International Journal of Smart and Nano Materials, 4, 2-26 (2013). https://doi.org/10.1080/19475411.2011.652218

[25] Liu G., Chen Y., Li R-W., Zhang B., Kang E-T., Wang C., Zhuang X.: Resistance-switchable graphene oxidepolymer nanocomposites for molecular electronics. ChemElectroChem, 1, 514-519 (2014). https://doi.org/10.1002/celc.201300158

[26] Cazacu M., Ignat M., Racles C., Cristea M., Musteata V., Ovezea D., Lipcinski D.: Well-defined silicone-titania composites with good performances in actuation and energy harvesting. Journal of Composite Materials, 48, 1533-1545 (2014).

https://doi.org/10.1177/0021998313488148

[27] Zhao W., Shi Z., Hu S., Yang G., Tian H.: Understanding piezoelectric characteristics of PHEMA-based hydrogel nanocomposites as soft self-powered electronics. Advanced Composites and Hybrid Materials, 1, 320-331 (2018). https://doi.org/10.1007/s42114-018-0036-3 
[28] Ziółkowski B., Czugala M., Diamond D.: Integrating stimulus responsive materials and microfluidics: The key to next-generation chemical sensors. Journal of Intelligent Material Systems and Structures, 24, 22212238 (2012). https://doi.org/10.1177/1045389X12459591

[29] Rivero R. E., Molina M. A., Rivarola C. R., Barbero C. A.: Pressure and microwave sensors/actuators based on smart hydrogel/conductive polymer nanocomposite. Sensors and Actuators B: Chemical, 190, 270-278 (2014). https://doi.org/10.1016/j.snb.2013.08.054

[30] Kharroub S., Laflamme S., Madbouly S., Ubertini F.: Bio-based soft elastomeric capacitor for structural health monitoring applications. Structural Health Monitoring, 14, 158-167 (2015). https://doi.org/10.1177/1475921714560072

[31] Kim H., Wilburn B. R., Castro E., Garcia Rosales C. A., Chavez L. A., Bill Tseng T-L., Lin Y.: Multifunctional Sensing using 3D printed $\mathrm{CNTs} / \mathrm{BaTiO}_{3} / \mathrm{PVDF}$ nanocomposites. Journal of Composite Materials, 53, 13191328 (2019). https://doi.org/10.1177/0021998318800796

[32] Hilber W.: Stimulus-active polymer actuators for nextgeneration microfluidic devices. Applied Physics A, 122, 751/1-751/39 (2016). https://doi.org/10.1007/s00339-016-0258-6

[33] Han I. K., Chung T. H., Han J., Kim Y. S.: Nanocomposite hydrogel actuators hybridized with various dimensional nanomaterials for stimuli responsiveness enhancement. Nano Convergence, 6, 18/1-18/21 (2019). https://doi.org/10.1186/s40580-019-0188-z

[34] Wu W.: Stretchable electronics: Functional materials, fabrication strategies and applications. Science and Technology of Advanced Materials, 20, 187-224 (2019). https://doi.org/10.1080/14686996.2018.1549460

[35] Honarvar M. G., Latifi M.: Overview of wearable electronics and smart textiles. The Journal of the Textile Institute, 108, 631-652 (2017). https://doi.org/10.1080/00405000.2016.1177870

[36] Lou Z., Wang L., Shen G.: Recent advances in smart wearable sensing systems. Advanced Materials Technologies, 3, 1800444/1-1800444/17 (2018). https://doi.org/10.1002/admt.201800444

[37] Zakerzadeh E., Alizadeh E., Kafil H. S., Hassanzadeh A. M., Salehi R., Mahkam M.: Novel antibacterial polymeric nanocomposite for smart co-delivery of anticancer drugs. Artificial Cells, Nanomedicine, and Biotechnology, 45, 1509-1520 (2017). https://doi.org/10.1080/21691401.2016.1260576

[38] Seyfoori A., Sarfarazijami S., Seyyed Ebrahimi S. A.: pH-responsive carbon nanotube-based hybrid nanogels as the smart anticancer drug carrier. Artificial Cells, Nanomedicine, and Biotechnology, 47, 1437-1443 (2019).

https://doi.org/10.1080/21691401.2019.1596939
[39] Bashir M., Rajendran P.: A review on electroactive polymers development for aerospace applications. Journal of Intelligent Material Systems and Structures, 29, 3681-3695 (2018). https://doi.org/10.1177/1045389X18798951

[40] Vertuccio L., Guadagno L., Spinelli G., Lamberti P., Zarrelli M., Russo S., Iannuzzo G.: Smart coatings of epoxy based CNTs designed to meet practical expectations in aeronautics. Composites Part B: Engineering, 147, 42-46 (2018).

https://doi.org/10.1016/j.compositesb.2018.04.027

[41] Ratna D., Karger-Kocsis J.: Recent advances in shape memory polymers and composites: A review. Journal of Materials Science, 43, 254-269 (2008). https://doi.org/10.1007/s10853-007-2176-7

[42] Fan K., Huang W. M., Wang C. C., Ding Z., Zhao Y., Purnawali H., Liew K. C., Zheng L. X.: Water-responsive shape memory hybrid: Design concept and demonstration. Express Polymer Letters, 5, 409-416 (2011). https://doi.org/10.3144/expresspolymlett.2011.40

[43] Urbina L., Alonso-Varona A., Saralegi A., Palomares T., Eceiza A., Corcuera M. A., Retegi A.: Hybrid and biocompatible cellulose/polyurethane nanocomposites with water-activated shape memory properties. Carbohydrate Polymers, 216, 86-96 (2019). https://doi.org/10.1016/j.carbpol.2019.04.010

[44] Ahmad H.: Biocompatible $\mathrm{SiO}_{2}$ in the fabrication of stimuli-responsive hybrid composites and their application potential. Journal of Chemistry, 2015, 8463281/1-8463281/19 (2015).

https://doi.org/10.1155/2015/846328

[45] Liu Y., Lv H., Lan X., Leng J., Du S.: Review of electro-active shape-memory polymer composite. Composites Science and Technology, 69, 2064-2068 (2009).

https://doi.org/10.1016/j.compscitech.2008.08.016

[46] Lu H., Liu Y., Leng J., Du S.: Qualitative separation of the physical swelling effect on the recovery behavior of shape memory polymer. European Polymer Journal, 46, 1908-1914 (2010). https://doi.org/10.1016/j.eurpolymj.2010.06.013

[47] Fejős M., Karger-Kocsis J.: Shape memory performance of asymmetrically reinforced epoxy/carbon fibre fabric composites in flexure. Express Polymer Letters, 7, 528-534 (2013). https://doi.org/10.3144/expresspolymlett.2013.49

[48] Yan W., Fang L., Noechel U., Kratz K., Lendlein A.: Influence of deformation temperature on structural variation and shape-memory effect of a thermoplastic semicrystalline multiblock copolymer. Express Polymer Letters, 9, 624-635 (2015). https://doi.org/10.3144/expresspolymlett.2015.58

[49] Meng H., Li G.: A review of stimuli-responsive shape memory polymer composites. Polymer, 54, 2199-2221 (2013). https://doi.org/10.1016/j.polymer.2013.02.023 
[50] Lu H., Wang X., Yu K., Huang W. M., Yao Y., Leng J.: A phenomenological formulation for the shape/temperature memory effect in amorphous polymers with multi-stress components. Smart Materials and Structures, 26, 095011/1-095011/11 (2017). https://doi.org/10.1088/1361-665X/aa77b3

[51] Karger-Kocsis J., Kéki S.: Biodegradable polyesterbased shape memory polymers: Concepts of (supra)molecular architecturing. Express Polymer Letters, 8, $397-$ 412 (2014).

https://doi.org/10.3144/expresspolymlett.2014.44

[52] Panahi-Sarmad M., Abrisham M., Noroozi M., Amirkiai A., Dehghan P., Goodarzi V., Zahiri B.: Deep focusing on the role of microstructures in shape memory properties of polymer composites: A critical review. European Polymer Journal, 117, 280-303 (2019). https://doi.org/10.1016/j.eurpolymj.2019.05.013

[53] Kolesov I., Dolynchuk O., Radusch H-J.: Shape-memory behavior of cross-linked semi-crystalline polymers and their blends. Express Polymer Letters, 9, 255-276 (2015) https://doi.org/10.3144/expresspolymlett.2015.24

[54] Cao Z-Q., Wang G-J.: Multi-stimuli-responsive polymer materials: Particles, films, and bulk gels. The Chemical Record, 16, 1398-1435 (2016). https://doi.org/10.1002/tcr.201500281

[55] Schmidt A. M.: Thermoresponsive magnetic colloids. Colloid and Polymer Science, 285, 953-966 (2007). https://doi.org/10.1007/s00396-007-1667-z

[56] Le D. M., Tycon M. A., Fecko C. J., Ashby V. S.: Near-infrared activation of semi-crystalline shape memory polymer nanocomposites. Journal of Applied Polymer Science, 130, 4551-4557 (2013).

https://doi.org/10.1002/APP.39604

[57] Patel D. K., Seo Y-R., Lim K-T.: Stimuli-responsive graphene nanohybrids for biomedical applications. Stem Cells International, 2019, 9831853/1-9831853/18 (2019) https://oi.org/10.1155/2019/9831853

[58] Kim H-N., Yang S.: Responsive smart windows from nanoparticle-polymer composites. Advanced Functional Materials, 2019, 1902597/1-1902597/25 (2019). https://doi.org/10.1002/adfm.201902597

[59] Tsujimoto T., Ohta E., Uyama H.: Plant oil-based shape memory polymer using acrylic monolith. Express Polymer Letters, 9, 757-763 (2015). https://doi.org/10.3144/expresspolymlett.2015.71

[60] Li J., Duan Q., Zhang E., Wang J.: Applications of shape memory polymers in kinetic buildings. Advances in Materials Science and Engineering, 2018, 7453698/17453698/13 (2018). https://doi.org/10.1155/2018/7453698

[61] Kostopoulos V., Kotrotsos A., Baltopoulos A., Tsantzalis S., Tsokanas P., Loutas T., Bosman A. W.: Mode II fracture toughening and healing of composites using supramolecular polymer interlayers. Express Polymer Letters, 10, 914-926 (2016).

https://doi.org/10.3144/expresspolymlett.2016.85
[62] Zhang Q., Liu L., Pan C., Li D.: Review of recent achievements in self-healing conductive materials and their applications. Journal of Materials Science, 53, 27-46 (2018).

https://doi.org/10.1007/s10853-017-1388-8

[63] Yuan Y. C., Yin T., Rong M. Z., Zhang M. Q.: Self healing in polymers and polymer composites. Concepts, realization and outlook: A review. Express Polymer Letters, 2, 238-250 (2008).

https://doi.org/10.3144/expresspolymlett.2008.29

[64] Szmechtyk T., Sienkiewicz N., Strzelec K.: Thermally induced self-healing epoxy/glass laminates with porous layers containing crystallized healing agent. Express Polymer Letters, 12, 640-648 (2018). https://doi.org/10.3144/expresspolymlett.2018.54

[65] Vijayan P., AlMaadeed M. A.: 'Containers' for selfhealing epoxy composites and coating: Trends and advances. Express Polymer Letters, 10, 506-524 (2016). https://doi.org/10.3144/expresspolymlett.2016.48

[66] Aïssa B., Tagziria K., Haddad E., Jamroz W., Loiseau J., Higgins A., Asgar-Khan M., Hoa S. V., Merle P. G., Therriault D., Rosei F.: The self-healing capability of carbon fibre composite structures subjected to hypervelocity impacts simulating orbital space debris. ISRN Nanomaterials, 2012, 351205/1-351205/16 (2012). https://doi.org/10.5402/2012/351205

[67] Zhao L., Jiang B., Huang Y.: Functionalized graphene-reinforced polysiloxane nanocomposite with improved mechanical performance and efficient healing properties. Journal of Applied Polymer Science, 136, 47725/1-47725/11 (2019). https://doi.org/10.1002/APP.47725

[68] Formia A., Irico S., Bertola F., Canonico F., Antonaci P., Pugno N. M., Tulliani J-M.: Experimental analysis of self-healing cement-based materials incorporating extruded cementitious hollow tubes. Journal of Intelligent Material Systems and Structures, 27, 2633-2652 (2016). https://doi.org/10.1177/1045389X16635847

[69] You Y-Z., Hong C-Y., Pan C-Y.: Preparation of smart polymer/carbon nanotube conjugates via stimuli-responsive linkages. Advanced Functional Materials, 17, 2470-2477 (2007). https://doi.org/10.1002/adfm.200600742

[70] Narendra Kumar U., Kratz K., Behl M., Lendlein A.: Shape-memory properties of magnetically active tripleshape nanocomposites based on a grafted polymer network with two crystallizable switching segments. Express Polymer Letters, 6, 26-40 (2012). https://doi.org/10.3144/expresspolymlett.2012.4

[71] Cai Y., Jiang J-S., Zheng B., Xie M-R.: Synthesis and properties of magnetic sensitive shape memory $\mathrm{Fe}_{3} \mathrm{O}_{4} /$ poly( $\varepsilon$-caprolactone)-polyurethane nanocomposites. Journal of Applied Polymer Science, 127, 49-56 (2013). https://doi.org/10.1002/app.36849 
[72] Kalita H., Karak N.: Bio-based hyperbranched polyurethane $/ \mathrm{Fe}_{3} \mathrm{O}_{4}$ nanocomposites as shape memory materials. Polymers Advanced Technologies, 24, 819-823 (2013).

https://doi.org/10.1002/pat.3149

[73] Gao Y., Zhu G., Xu S., Ma T., Nie J.: Biodegradable magnetic-sensitive shape memory poly( $\varepsilon$-caprolactone $) / \mathrm{Fe}_{3} \mathrm{O}_{4}$ nanocomposites. Journal of Applied Polymer Science, 135, 45652/1-45652/9 (2018).

https://doi.org/10.1002/APP.45652

[74] Kurd K., Khandagi A. A., Davaran S., Akbarzadeh A.: Cisplatin release from dual-responsive magnetic nanocomposites. Artificial Cells, Nanomedicine, and Biotechnology, 44, 1031-1039 (2016).

https://doi.org/10.3109/21691401.2015.1008513

[75] Ahmadkhani L., Akbarzadeh A., Abbasian M.: Development and characterization dual responsive magnetic nanocomposites for targeted drug delivery systems. Artificial Cells, Nanomedicine, and Biotechnology, 46, 1052-1063 (2018).

https://doi.org/10.1080/21691401.2017.1360323

[76] Lakatos Cs., Czifrák K., Papp R., Karger-Kocsis J., Zsuga M., Kéki S.: Segmented linear shape memory polyurethanes with thermoreversible Diels-Alder coupling: Effects of polycaprolactone molecular weight and diisocyanate type. Express Polymer Letters, 10, 324-336 (2016).

https://doi.org/10.3144/expresspolymlett.2016.30

[77] Abbasi A., Sadeghi G. M. M., Ghasemi I., Shahrousvand M.: Shape memory performance of green in situ polymerized nanocomposites based on polyurethane/ graphene nanoplatelets: Synthesis, properties, and cell behavior. Polymer Composites, 39, 4020-4033 (2018). https://doi.org/10.1002/pc.24456

[78] Liu G., Ding X., Cao Y., Zheng Z., Peng Y.: Novel shape-memory polymer with two transition temperatures. Macromolecular Rapid Communications, 26, 649-652 (2005). https://doi.org/10.1002/marc.200400640

[79] Liu G., Guan C., Xia H., Guo F., Ding X., Peng Y.: Novel shape-memory polymer based on hydrogen bonding. Macromolecular Rapid Communications, 27, 1100-1104 (2006).

https://doi.org/10.1002/marc.200600189

[80] Ghosh T., Karak N.: Multi-walled carbon nanotubes reinforced interpenetrating polymer network with ultrafast self-healing and anti-icing attributes. Journal of Colloid and Interface Science, 540, 247-257 (2019). https://doi.org/10.1016/j.jcis.2019.01.006

[81] Yan B., Gu S., Zhang Y.: Polylactide-based thermoplastic shape memory polymer nanocomposites. European Polymer Journal, 49, 366-378 (2013). https://doi.org/10.1016/j.eurpolymj.2012.09.026

[82] Gu S., Yan B., Liu L., Ren J.: Carbon nanotube-polyurethane shape memory nanocomposites with low trigger temperature. European Polymer Journal, 49, 3867 3877 (2013).

https://doi.org/10.1016/j.eurpolymj.2013.10.007
[83] Navarro-Baena I., Kenny J. M., Peponi L.: Thermally-activated shape memory behaviour of bionanocomposites reinforced with cellulose nanocrystals. Cellulose, 21, 4231-4246 (2014). https://doi.org/10.1007/s10570-014-0446-5

[84] Sessini V., Brox D., López A. J., Ureña A., Peponi L.: Thermally activated shape memory behavior of copolymers based on ethylene reinforced with silica nanoparticles. Nanocomposites, 4, 19-35 (2018). https://doi.org/10.1080/20550324.2018.1472723

[85] Eshkaftaki F. J., Ghasemi I.: Multiple-shape memory behavior of nanocomposite based on polymethylmethacrylate/poly (lactic acid)/graphene nanoplatelets (PMMA/PLA/GNP). Polymer Bulletin, 75, 40734084 (2018).

https://doi.org/10.1007/s00289-017-2252-3

[86] Lashgari S., Karrabi M., Ghasemi I., Azizi H., Messori M., Paderni K.: Shape memory nanocomposite of poly (L-lactic acid)/graphene nanoplatelets triggered by infrared light and thermal heating. Express Polymer Letters, 10, 349-359 (2016).

https://doi.org/10.3144/expresspolymlett.2016.32

[87] Luo H., Hu J., Zhu Y.: Polymeric shape memory nanocomposites with heterogeneous twin switches. Macromolecular Chemistry and Physics, 212, 1981-1986 (2011). https://doi.org/10.1002/macp.201100292

[88] Ahmed N., Kausar A., Muhammad B.: Shape memory properties of electrically conductive multi-walled carbon nanotube-filled polyurethane/modified polystyrene blends. Journal of Plastic Film and Sheeting, 32, 272-292 (2016). https://doi.org/10.1177/8756087915595454

[89] Zhong A., He Z., Zhang H., Xiong L., Xu Y., Wang T., Zhou M., Huang K.: Facile synthesis of Au@PNIPAM- $b$-PPy nanocomposites with thermosensitive and photothermal effects. Journal of Polymer Science Part A: Polymer Chemistry, 54, 3079-3085 (2016). https://doi.org/10.1002/pola.28190

[90] Qian C., Zhu Y., Dong Y., Fu Y.: Vapor-grown carbon nanofiber/poly(ethylene-co-vinyl acetate) composites with electrical-active two-way shape memory behavior. Journal of Intelligent Material Systems and Structures, 28, 2749-2756 (2017).

https://doi.org/10.1177/1045389X17698246

[91] Molavi F. K., Ghasemi I., Messori M., Esfandeh M.: Nanocomposites based on poly(L-lactide)/poly( $\varepsilon$-caprolactone) blends with triple-shape memory behavior: Effect of the incorporation of graphene nanoplatelets (GNps). Composites Science and Technology, 151 219-227 (2017). https://doi.org/10.1016/j.compscitech.2017.08.021 
[92] Abbasi-Shirsavar M., Baghani M., Taghavimehr M., Golzar M., Nikzad M., Ansari M., George D.: An experimental-numerical study on shape memory behavior of PU/PCL/ZnO ternary blend. Journal of Intelligent Material Systems and Structures, 30, 116-126 (2019).

https://doi.org/10.1177/1045389X18803459

[93] Gu S-Y., Chang K., Jin S-P.: A dual-induced self-expandable stent based on biodegradable shape memory polyurethane nanocomposites $\left(\mathrm{PCLAU} / \mathrm{Fe}_{3} \mathrm{O}_{4}\right)$ triggered around body temperature. Journal of Applied Polymer Science, 135, 45686/1-45686/10 (2018). https://doi.org/10.1002/APP.45686

[94] Zou G., Shen J., Duan P., Xia X., Chen R., Jin B.: Temperature-sensitive poly $(N$-isopropylacrylamide $) /$ konjac glucomannan/graphene oxide composite membranes with improved mechanical property, swelling capability, and degradability. International Journal of Polymer Science, 2018, 7906747/1-7906747/10 (2018). https://doi.org/10.1155/2018/7906747

[95] Cellini F., Block L., Li J., Khapli S., Peterson S. D., Porfiri M.: Mechanochromic response of pyrene functionalized nanocomposite hydrogels. Sensors and Actuators B: Chemical, 234, 510-520 (2016).

https://doi.org/10.1016/j.snb.2016.04.149

[96] Mordina B., Kumar R., Setua D. K., Sharma A.: Smart elastomeric hydrogel of polyacrylamide containing nanosized barium ferrite and graphene oxide. Journal of Composite Materials, 53, 3139-3156 (2019). https://doi.org/10.1177/0021998319839128

[97] Guo J., Li L., Ti Y., Zhu J.: Synthesis and properties of a novel $\mathrm{pH}$ sensitive poly( $\mathrm{N}$-vinyl-pyrrolidone- $\mathrm{co}$ sulfadiazine) hydrogel. Express Polymer Letters, 1, 166-172 (2007). https://doi.org/10.3144/expresspolymlett.2007.26

[98] Casolaro M., Ito Y., Ishii T., Bottari S., Samperi F., Mendichi R.: Stimuli-responsive poly(ampholyte)s containing L-histidine residues: Synthesis and protonation thermodynamics of methacrylic polymers in the free and in the cross-linked gel forms. Express Polymer Letters, 2, 165-183 (2008). https://doi.org/10.3144/expresspolymlett.2008.22

[99] Yu Y., Liu Y., Jia F., Li S., Kong Y., Zhang E. C.: Synthesis and characterization of temperature-sensitive poly $(\mathrm{N}$-isopropylacryamide-co-acrylamide)/montmorillonite nanocomposite hydrogels. International Journal of Polymeric Materials, 62, 34-38 (2013).

https://doi.org/10.1080/00914037.2011.641699

[100] Liu Z., Faraj Y., Ju X-J., Wang W., Xie R., Chu L-Y.: Nanocomposite smart hydrogels with improved responsiveness and mechanical properties: A mini review. Journal of Polymer Science Part B: Polymer Physics, 56, 1306-1313 (2018).

https://doi.org/10.1002/polb.24723
[101] Czakkel O., Berke B., László K.: Effect of graphenederivatives on the responsivity of PNIPAM-based thermosensitive nanocomposites - A review. European Polymer Journal, 116, 106-116 (2019). https://doi.org/10.1016/j.eurpolymj.2019.04.004

[102] Haraguchi K.: Stimuli-responsive nanocomposite gels. Colloid and Polymer Science, 289, 455-473 (2011). https://doi.org/10.1007/s00396-010-2373-9

[103] Yassine O., Li E. Q., Alfadhel A., Zaher A., Kavaldzhiev M., Thoroddsen S. T., Kosel J.: Magnetically triggered monodispersed nanocomposite fabricated by microfluidic approach for drug delivery. International Journal of Polymer Science, 2016, 1219469/1-1219469/8 (2016). https://doi.org/10.1155/2016/1219469

[104] Ahmad H., Sultana M. S., Alam M. A., Rahman M. M., Tauer K., Gafur M. A., Sharafat M. K.: Evaluating a simple blending approach to prepare magnetic and stimuli-responsive composite hydrogel particles for application in biomedical field. Express Polymer Letters, 10, 664-678 (2016).

https://doi.org/10.3144/expresspolymlett.2016.60

[105] Hou K., Wu W., Xia M., Zhu M.: A novel NIR laser switched nanocomposite hydrogel as remote stimuli smart valve. Macromolecular Materials and Engineering, 302, 1700213/1-1700213/10 (2017).

https://doi.org/10.1002/mame.201700213

[106] Devaux E., Koncar V., Kim B., Campagne C., Roux C., Rochery M., Saihi D.: Processing and characterization of conductive yarns by coating or bulk treatment for smart textile applications. Transactions of the Institute of Measurement and Control, 29, 355-376 (2007). https://doi.org/10.1177/0142331207081726

[107] Zhuo H. T., Hu J. L., Chen S. J.: Coaxial electrospun polyurethane core-shell nanofibers for shape memory and antibacterial nanomaterials. Express Polymer Letters, 5, 182-187 (2011).

https://doi.org/10.3144/expresspolymlett.2011.16

[108] Tonndorf R., Kirsten M., Hund R-D., Cherif C.: Designing UV/VIS/NIR-sensitive shape memory filament yarns. Textile Research Journal, 85, 1305-1316 (2015). https://doi.org/10.1177/0040517514559578

[109] Sabzi M., Ranjbar-Mohammadi M., Zhang Q., Kargozar S., Leng J., Akhtari T., Abbasi R.: Designing triple-shape memory polymers from a miscible polymer pair through dual-electrospinning technique. Journal of Applied Polymer Science, 136, 47471/147471/10 (2019). https://doi.org/10.1002/APP.47471

[110] Harsch M., Karger-Kocsis J., Herzog F.: Strain development in a filled epoxy resin curing under constrained and unconstrained conditions as assessed by Fibre Bragg grating sensors. Express Polymer Letters, 1, 226-231 (2007). https://doi.org/10.3144/expresspolymlett.2007.34 
[111] Xie F., Huang L., Leng J., Liu Y.: Thermoset shape memory polymers and their composites. Journal of Intelligent Material Systems and Structures, 27, 24332455 (2016). https://doi.org/10.1177/1045389X16634211

[112] Karger-Kocsis J., Kéki S.: Review of progress in shape memory epoxies and their composites. Polymers, 10, $1-38$ (2018).

https://doi.org/10.3390/polym10010034

[113] Fejős M., Molnár K., Karger-Kocsis J.: Epoxy/polycaprolactone systems with triple-shape memory effect: Electrospun nanoweb with and without graphene versus co-continuous morphology. Materials, 6, 44894504 (2013). https://doi.org/10.3390/ma6104489

[114] Li X., Zhu Y., Dong Y., Liu M., Ni Q., Fu Y.: Epoxy resin composite bilayers with triple-shape memory effect. Journal of Nanomaterials, 2015, 47531614753161/8 (2015). https://doi.org/10.1155/2015/475316

[115] Ortiz R. A., Garcia Valdez A. E., Arguello G. S., Padilla G. M., Berlanga O. A.: Photocurable shape-memory polyether-polythioether/graphene nanocomposites and the study of their thermal conductivity. Journal of Polymer Research, 25, 160/1-160/11 (2018).

https://doi.org/10.1007/s10965-018-1552-0

[116] Ivens J., Urbanus M., De Smet C.: Shape recovery in a thermoset shape memory polymer and its fabric-reinforced composites. Express Polymer Letters, 5, 254 261 (2011).

https://doi.org/10.3144/expresspolymlett.2011.25

[117] Abishera R., Velmurugan R., Nagendra Gopal K. V.: Free, partial, and fully constrained recovery analysis of cold-programmed shape memory epoxy/carbon nanotube nanocomposites: Experiments and predictions. Journal of Intelligent Material Systems and Structures, 29, 2164-2176 (2018). https://doi.org/10.1177/1045389X18758187

[118] Liang F., Sivilli R., Gou J., Xu Y., Mabbott B.: Electrical actuation and shape recovery control of shapememory polymer nanocomposites. International Journal of Smart and Nano Materials, 4, 167-178 (2013). https://doi.org/10.1080/19475411.2013.837846

[119] Lu H., Yao Y., Huang W. M., Leng J., Hui D.: Significantly improving infrared light-induced shape recovery behavior of shape memory polymeric nanocomposite via a synergistic effect of carbon nanotube and boron nitride. Composites Part B: Engineering, 62, 256-261 (2014).

https://doi.org/10.1016/j.compositesb.2014.03.007

[120] Tanpitaksit T., Jubsilp C., Rimdusit S.: Effects of benzoxazine resin on property enhancement of shape memory epoxy: A dual function of benzoxazine resin as a curing agent and a stable network segment. Express Polymer Letters, 9, 824-837 (2015). https://doi.org/10.3144/expresspolymlett.2015.77
[121] Zhang X., Yang P., Dai Y., Ma P., Li X., Cheng Z., Hou Z., Kang X., Li C., Lin J.: Multifunctional up-converting nanocomposites with smart polymer brushes gated mesopores for cell imaging and thermo/pH dual-responsive drug controlled release. Advanced Functional Materials, 23, 4067-4078 (2013).

https://doi.org/10.1002/adfm.201300136

[122] Sim B., Chae H. S., Choi H. J.: Fabrication of polyaniline coated iron oxide hybrid particles and their dual stimuli-response under electric and magnetic fields. Express Polymer Letters, 9, 736-743 (2015). https://doi.org/10.3144/expresspolymlett.2015.68

[123] Zhang T., Zhang W., Wang B., Liu J.: One-step synthesis of core/shell-like structured polypyrrole/sodium alginate nanocomposites and their electro-responsive performances. Journal of Intelligent Material Systems and Structures, 29, 232-241 (2018). https://doi.org/10.1177/1045389X17733055

[124] Kang S. M., Kwon S. H., Park J. H., Kim B. K.: Carbon nanotube reinforced shape memory polyurethane foam. Polymer Bulletin, 70, 885-893 (2013). https://doi.org/10.1007/s00289-013-0905-4

[125] Mendes-Felipe C., Oliveira J., Etxebarria I., VilasVilela J. L., Lanceros-Mendez S.: State-of-the-art and future challenges of UV curable polymer-based smart materials for printing technologies. Advanced Materials Technologies, 4, 1800618/1-1800618/16 (2019). https://doi.org/10.1002/admt.201800618

[126] Lee S. K., Yoon S. H., Chung I., Hartwig A., Kim B. K.: Waterborne polyurethane nanocomposites having shape memory effects. Journal of Polymer Science Part A: Polymer Chemistry, 49, 634-641 (2011). https://doi.org/10.1002/pola.24473

[127] Szebényi G., Czigány T., Magyar B., Karger-Kocsis J.: $3 \mathrm{D}$ printing-assisted interphase engineering of polymer composites: Concept and feasibility. Express Polymer Letters, 11, 525-530 (2017). https://doi.org/10.3144/expresspolymlett.2017.50

[128] Cui H., Miao S., Esworthy T., Lee S-J., Zhou X., Hann S. Y., Webster T. J., Harris B. T., Grace Zhang L.: A novel near-infrared light responsive 4D printed nanoarchitecture with dynamically and remotely controllable transformation. Nano Research, 12, 1381-1388 (2019). https://doi.org/10.1007/s12274-019-2340-9

[129] Chow W. S., Mohd Ishak Z. A.: Polyamide blendbased nanocomposites: A review. Express Polymer Letters, 9, 211-232 (2015). https://doi.org/10.3144/expresspolymlett.2015.22

[130] Yin C., Zeng H., Gu J., Xie Z., Sun H.: Modeling the thermomechanical behaviors of particle reinforced shape memory polymer composites. Applied Physics A, 125, 382/1-382/10 (2019). https://doi.org/10.1007/s00339-019-2672-z

[131] Xin X., Liu L., Liu Y., Leng J.: Mechanical models, structures, and applications of shape-memory polymers and their composites. Acta Mechanica Solida Sinica, 32, 535-565 (2019). https://doi.org/10.1007/s10338-019-00103-9 